University of Nebraska - Lincoln

DigitalCommons@University of Nebraska - Lincoln

Educational Psychology Papers and

Publications

Educational Psychology, Department of

$2-1-2008$

\title{
Conjoint Behavioral Consultation: What Do We Know and What Do We Need to Know?
}

\author{
Susan M. Sheridan \\ University of Nebraska-Lincoln, ssheridan2@unl.edu \\ Brandy L. Clarke \\ University of Nebraska-Lincoln, brandy.clarke@unmc.edu \\ Jennifer D. Burt \\ University of Nebraska-Lincoln
}

Follow this and additional works at: https://digitalcommons.unl.edu/edpsychpapers

Part of the Educational Psychology Commons

Sheridan, Susan M.; Clarke, Brandy L.; and Burt, Jennifer D., "Conjoint Behavioral Consultation: What Do We Know and What Do We Need to Know?" (2008). Educational Psychology Papers and Publications. 73. https://digitalcommons.unl.edu/edpsychpapers/73

This Article is brought to you for free and open access by the Educational Psychology, Department of at DigitalCommons@University of Nebraska - Lincoln. It has been accepted for inclusion in Educational Psychology Papers and Publications by an authorized administrator of DigitalCommons@University of Nebraska - Lincoln. 
Published in Handbook of Research in School Consultation, edited by William P. Erchul and Susan M. Sheridan. Lawrence Erlbaum Associates Inc., New York, 2008. ISBN: 9780805853360

Copyright @ 2008 Taylor \& Francis Group LLC. Used by permission.

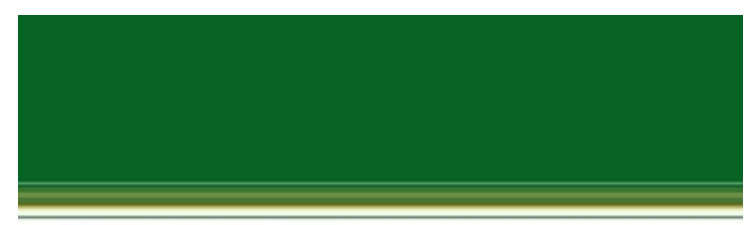

Handbook of Research in School Consultation 


\title{
Conjoint Behavioral Consultation What Do We Know and What Do We Need to Know?
}

\author{
Susan M. Sheridan, Brandy L. Clarke, and Jennifer D. Burt \\ University of Nebraska-Lincoln
}

\section{WHERE WE HAVE BEEN: BACKGROUND TO CONIOINT BEHAVIORAL CONSULTATION}

The importance of parent involvement and home-school partnerships has been clearly established (Christenson, 2004). Research has shown unequivocally that when parents are involved in their children's educational programs, children, families, classrooms, and schools all benefit (Christenson \& Sheridan, 2001). Professional organizations and the national government have also recognized the positive impact of home-school partnerships. Policy calls for schools to engage in deeper partnerships with parents and communities to meet the increasing academic, behavioral, and social needs of students (No Child Left Behind [NCLB], 2002). In fact, NCLB specifically calls for "local education agencies to assist school personnel to reach out to, communicate with, and work with parents as equal partners; implement and coordinate parent programs; and build ties between parents and the school" (Pub. L. 107-111, 1118). As a result, both the National Association of School Psychologists and the interorganizational School Psychology Futures Conference have identified the development of home-school partnership models as a top priority in the field (Christenson, 2004; Ysseldyke et al., 1997).

Strong, positive relationships between the home and school systems are essential in addressing the needs of children and families and have demonstrated positive outcomes for parents, students, and teachers alike (Haynes, Comer, \& Hamilton-Lee, 1989; Masten \& Coatsworth, 1998). However, few models have been specified and validated that bring families and schools together in joint problem solving and decision making within a consultation framework. Conjoint behavioral consultation $(\mathrm{CBC})$ is one exception. $\mathrm{CBC}$ is an indirect method of service delivery that facilitates a collaborative working relationship among the key individuals in a child's life by establishing linkages between the home and school systems. Given its conceptual importance to the model, collaboration is defined here as a relational process between participants by which unique information, expertise, values, and goals are shared, and the insight gleaned from each party is incorporated into a joint intervention and evaluation plan for which all bear some responsibility. 
Table 9.1 Overarching Goals and Objectives of Conjoint Behavioral Consultation

\section{Goals}

1. Promote academic, socioemotional, and behavioral outcomes for children through joint, mutual, crosssystem planning.

2. Promote parent engagement in which parental roles, beliefs, and opportunities for meaningful participation are clear, within a developmental, culturally sensitive context.

3. Establish and strengthen home-school partnerships on behalf of children's learning and development, immediately and over time.

\section{Outcome Objectives}

1. Obtain comprehensive and functional data over extended temporal and contextual bases.

2. Establish consistent treatment programs across settings.

3. Improve the skills, knowledge, or behaviors of all parties (i.e., family members, school personnel, and the child-client).

4. Monitor behavioral contrast and side effects systematically via cross-setting treatment agents.

5. Enhance generalization and maintenance of treatment effects via consistent programming across sources and settings.

6. Develop skills and competencies to promote further independent conjoint problem solving between the family and school personnel.

\section{Process Objectives}

1. Improve communication, knowledge, and understanding about family, child, and school.

2. Promote shared ownership and joint responsibility for problem solution.

3. Promote greater conceptualization of needs and concerns and increase perspective taking.

4. Strengthen relationships within and across systems.

5. Maximize opportunities to address needs and concerns across, rather than within, settings.

6. Increase shared (parent and teacher) commitments to educational goals.

7. Increase the diversity of expertise and resources available.

\section{Definition, Goals, and Objectives of Conjoint Behavioral Consultation}

Conjoint behavioral consultation is defined as "a systematic, indirect form of service delivery, in which parents and teachers are joined to work together to address the academic, social, or behavioral needs of an individual for whom both parties bear some responsibility" (Sheridan \& Kratochwill, 1992 , p. 22). It is a conceptual and functional extension of a traditional approach to behavioral consultation (BC) that articulates several goals and objectives above and beyond conventional consultation practice. In $\mathrm{CBC}$, a consultant facilitates a collaborative partnership through a problemsolving process designed to recognize the interconnections between the home and school settings (Sheridan \& Kratochwill, 1992).

There are several goals and objectives of $\mathrm{CBC}$, as summarized in Table 9.1. These goals include (a) promoting the academic, behavioral, and socioemotional outcomes for children through joint problem solving; (b) encouraging parent engagement; and (c) strengthening the relationship among systems on behalf of the child's learning and development (Sheridan \& Kratochwill, in press). Within the goals of $\mathrm{CBC}$ are several process and outcome objectives. Process (relational) objectives are concerned with building and promoting positive, constructive partnerships among systems. Outcome objectives are directed toward the child and child-oriented results that occur through joint problem solving and planning. 


\section{Stages of Conjoint Behavioral Consultation}

The goals and objectives of $\mathrm{CBC}$ are achieved via four stages implemented in a collaborative manner, involving formal meetings and informal contact between the consultant, parents, and teachers. These stages include (a) conjoint needs identification, (b) conjoint needs analysis, (c) cross-setting plan implementation, and (d) conjoint plan evaluation (Sheridan, Kratochwill, \& Bergan, 1996). Three of the four stages are initiated in the context of a structured interview with parents and teachers. Next are guidelines that operationally depict the CBC process. Refer to Sheridan et al. (1996) and Sheridan and Kratochwill (2007) for a detailed description of CBC.

\section{Conjoint Needs Identification}

The conjoint needs identification stage (previously considered the conjoint problem identification stage) provides a framework for parents and teachers to develop a collaborative working relationship. This stage is procedurally operationalized during the Conjoint Needs Identification Interview (CNII; previously referred to as Conjoint Problem Identification Interview [CPII]). During the CNII, the consultant works with consultees to identify the child's most salient needs across home and school settings. Based on the severity and the relationship with other behaviors, the consultees jointly select a target behavior and define it in concrete, operational terms. Joint responsibility is encouraged to identify the specific settings and goals to be the focus of consultation. Consultees then collaboratively establish valid procedures for collecting baseline data across home and school settings. The goals of the CNII go beyond the identification of the target behavior and data collection procedures to include facilitating a relationship between the parents and teacher. Throughout this stage, the consultant identifies the strengths and capabilities of the child, family, and school to promote competencies in all participants. The consultant also remains in close contact with consultees to assist with data collection, answer questions as they arise, and promote the working relationship between home and school.

\section{Conjoint Needs Analysis}

In the conjoint needs analysis stage of $\mathrm{CBC}$ (previously known as conjoint problem analysis), the consultant assists consultees in developing solutions across settings based on baseline behavioral data. The Conjoint Needs Analysis Interview (CNAI; previously the Conjoint Problem Analysis Interview [CPAI]) provides a context for the consultant and consultees jointly to (a) identify ecological variables across settings that might influence the attainment of the behavioral goal and (b) develop a meaningful, solution-focused plan to address the target behavior across home and school. The consultant elicits information from consultees to facilitate the identification of environmental factors or functional variables that assist in understanding presenting concerns and developing meaningful plans. In addition, equal participation of parents and teachers, as well as shared ownership of plan development and problem solution, are encouraged. Baseline data are explored to identify setting events (i.e., environmental conditions that are distal in time or place from the target behavior but influence its occurrence); ecological conditions (e.g., home or classroom variables such as seating arrangement, delivery of instructions, and distractions in the environment); and cross-setting variables (e.g., consistency in expectations or management of behavioral concerns) that may have an impact on the target behavior. The focus of discussion centers on environmental conditions rather than internal causes to link assessment effectively to intervention and to promote a solution-focused, strength-based approach to plan development. Efforts are made to identify the presence of common events that occur across settings and are responsible for the presentation or 
maintenance of the target behavior. Hypotheses are generated around environmental conditions that contribute to the target behavior, and a joint plan then is developed to address the needs of the child across home and school settings. Throughout this stage, the consultant continues to promote the working relationship between home and school by encouraging and validating parents' and teachers' perspectives and ideas about the target behavior and plan development.

\section{Plan Implementation}

In the third stage of $\mathrm{CBC}$ (cross-system plan implementation), parents and teachers implement the intervention in the home and school settings. During this stage, the consultant remains in close contact with the family and school (e.g., phone calls, e-mails, and personal visits) to provide support, ensure understanding of intervention procedures, and reinforce parent and teacher efforts. Research indicates that an expanded (i.e., cross-setting) behavioral intervention base is advantageous to encourage consistency across environments (Kratochwill \& Sheridan, 1990). The partnership between parents and teachers helps to ensure cross-setting consistency in treatment implementation and increases the potential for generalization and maintenance of positive outcomes.

The extent to which a treatment plan is implemented as intended is described as treatment integrity (Gresham, 1989; Noell, chapter 15, this volume). This variable is likely to mediate outcomes in consultation or the effectiveness of CBC. For this reason, it is critical for the consultant to use strategies to promote treatment integrity during the plan implementation phase. Treatment plans that are not implemented, or not implemented as intended, are less likely to produce positive child outcomes. Performance feedback is a particularly effective procedure to enhance treatment implementation (Noell et al., 2005). It consists of monitoring treatment implementation and providing feedback to the individual responsible for treatment delivery. Although there is little research supporting other strategies, it has been suggested that treatment integrity may also be enhanced by (a) providing consultees with specific written information regarding the plan; (b) providing training or feedback in intervention components (e.g., modeling, rehearsing, and feedback); and (c) requesting that consultees self-monitor their adherence to the treatment plan (Noell et al., 2005).

\section{Conjoint Plan Evaluation}

Conjoint plan evaluation is the final stage of $\mathrm{CBC}$. The aim of the Conjoint Plan Evaluation Interview (CPEI) is to analyze the behavioral data to determine the achievement of consultation goals and the efficacy of treatment across settings. Throughout this stage, the behavioral data are used to focus the discussion around a future course of action (e.g., continuation, termination, planning for maintenance and follow-up). Additional interviews are scheduled as needed. Furthermore, the consultant encourages parents and teachers to continue to use open communication methods (e.g., home-school notes, regular phone contact, and meetings) to promote partnering and problem solving in the future. Often, systematic methods of consultee and client follow-up are necessary to ensure maintenance of positive child outcomes and the parent-teacher relationship. If positive outcomes are not maintained, then it may be necessary for the consultant to conduct future problem analysis, plan development, or consultee training.

$\mathrm{CBC}$ is a partnership-centered approach to service delivery. The goals and objectives of the model equally address the attainment of positive child outcomes and the establishment of a working relationship among systems. Although this process is formally operationalized via structured interviews, it is important to recognize that $\mathrm{CBC}$ occurs in the context of ongoing reciprocal interactions rather than simply through a series of formal interviews. Many of the objectives for each stage occur outside the formal interviews (e.g., behavioral observations and relationship building). 
Further, positive outcomes for all participants are achieved in the context of a collaborative relationship with ongoing communication and dialogue vital for continued progress.

\section{WHAT WE KNOW: THE EMPIRICAL BASE FOR CONJOINT BEHAVIORAL CONSULTATION}

Along with the articulation of the principles and practice guidelines related to $C B C$, empirical studies of the model have been accumulating since the early 1990s. Numerous studies have focused on outcomes, communication processes, and social validation of $\mathrm{CBC}$. Findings generally have (a) lent support to the efficacy of the model, (b) gleaned insights into the nature of communication patterns and relational features of practice, and (c) suggested positive perceptions by consumers of $\mathrm{CBC}$ services. These research areas are reviewed below.

\section{Review of Conjoint Behavioral Consultation Outcome Research}

Outcome research assessing the efficacy of $\mathrm{CBC}$ is growing. Numerous studies have been conducted evaluating the efficacy of $\mathrm{CBC}$ across home and school settings, in relation to academic, social, and behavioral outcomes, using experimental and case study methodologies. Table 9.2 presents a list of published studies summarized by authors, sample, target behavior, measures, results, methodological features (e.g., social validity assessment, fidelity information, and follow-up), and limitations.

A total of 13 studies have been published investigating the effects of $\mathrm{CBC}$. The most common target concern identified in CBC research is behavioral in nature (e.g., compliance and aggression), with 6 studies addressing behavioral issues. Two studies addressed social concerns (e.g., social withdrawal), and 2 addressed academic concerns (e.g., work completion and accuracy). Common methods used to assess outcomes across studies are direct observations and behavioral rating scales. In some studies, data on acceptability and satisfaction were also reported. In these studies, common measures are the Behavior Intervention Rating Scale (BIRS) Acceptability factor (Elliott \& Von Brock Treuting, 1991) revised for CBC (Sheridan, Eagle, Cowan, \& Mickelson, 2001) and the Consultant Evaluation Form (CEF; Erchul, 1987). Both experimental (e.g., multiple baseline, pretest-posttest randomized control) and case study designs were used. The majority of studies assessed clinical meaningfulness and perceptions of intervention effectiveness (i.e., social validity) using scales such as the BIRS Effectiveness factor (Elliott \& Von Brock Treuting, 1991) and Goal Attainment Scaling (GAS; Kiresuk, Smith, \& Cardillo, 1994). In addition, most reported integrity of implementing CBC (i.e., process integrity).

In this section, we summarize three large-scale reviews of CBC research (Guli, 2005; Sheridan et al., 2001; Sheridan, Eagle, \& Doll, 2006). A description of individual studies follows, organized as reviews of studies using (a) experimental outcome designs and (b) case study methods. In addition to the published studies reviewed here, a number of unpublished dissertation studies have been completed (e.g., Brown, 2004; Cagle, 2003; Colton, 1999; Finn, 2003; Illsley, 2003; Lasecki, 2001; Lepage, 1999; Morganstein, 2003; Moscovitz, 2004; Mulgia, 2001; Myers, 1997; Schnoes, 2003; Scope, 2003; Stephan, 1999). Due to space constraints, these are not be reviewed here, but interested readers are referred to relevant Dissertation Abstracts International sources for complete studies.

\section{Reviews and Meta-Analyses}

Guli (2005) conducted an extensive search of parent consultation literature using rigorous criteria specified in the Procedural and Coding Manual of the Division 16 Task Force on Evidence-Based Interventions in School Psychology (Kratochwill \& Stoiber, 2002). The majority of the 18 studies identified used single-participant designs, including both within-participant and multiple-baseline 


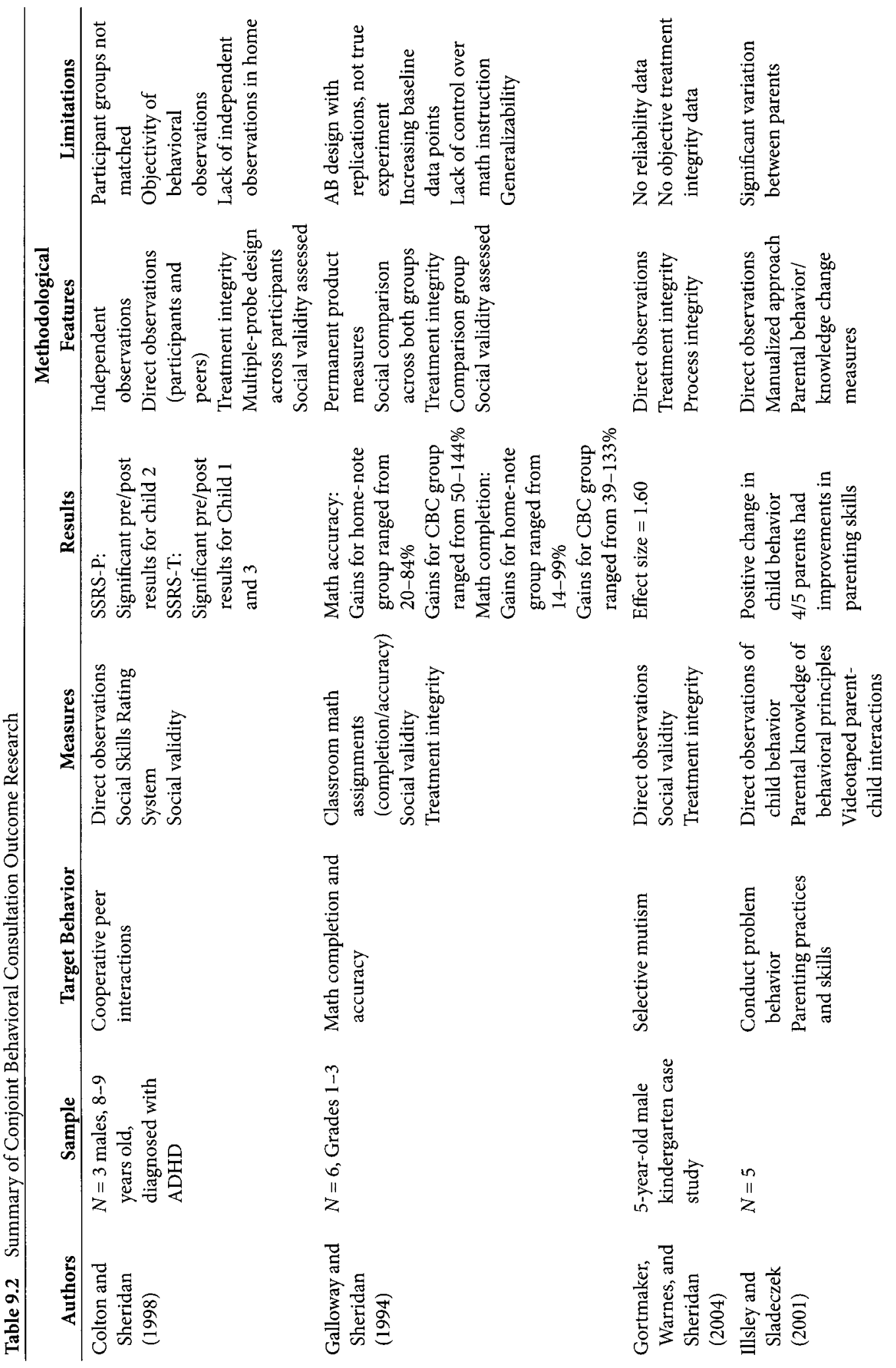




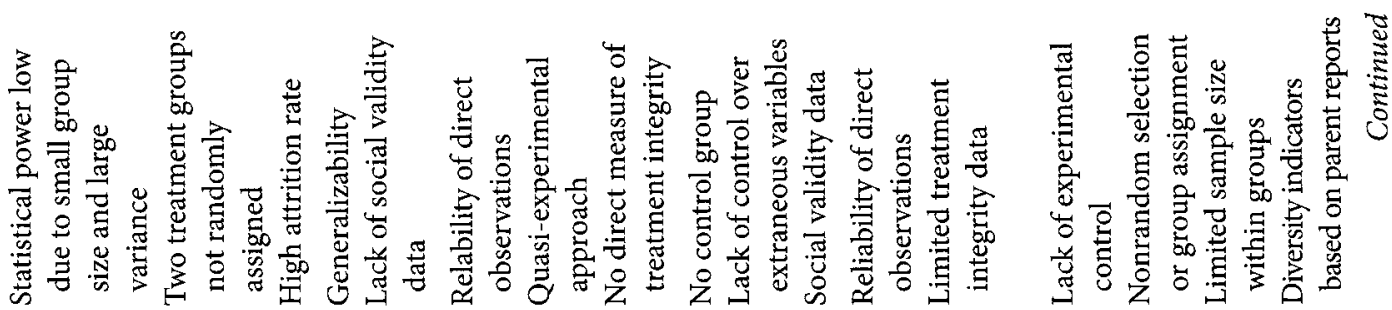

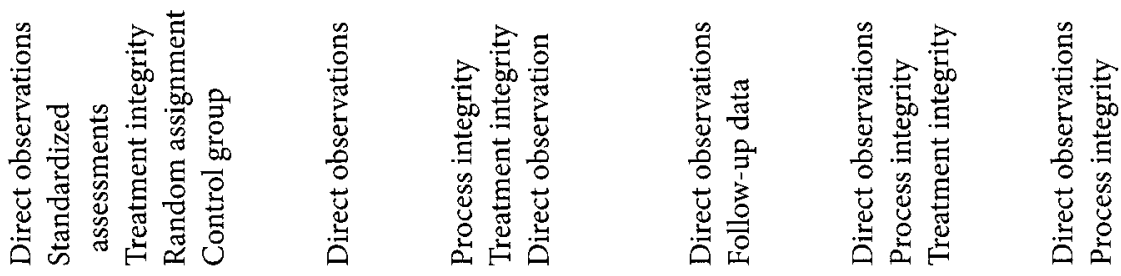
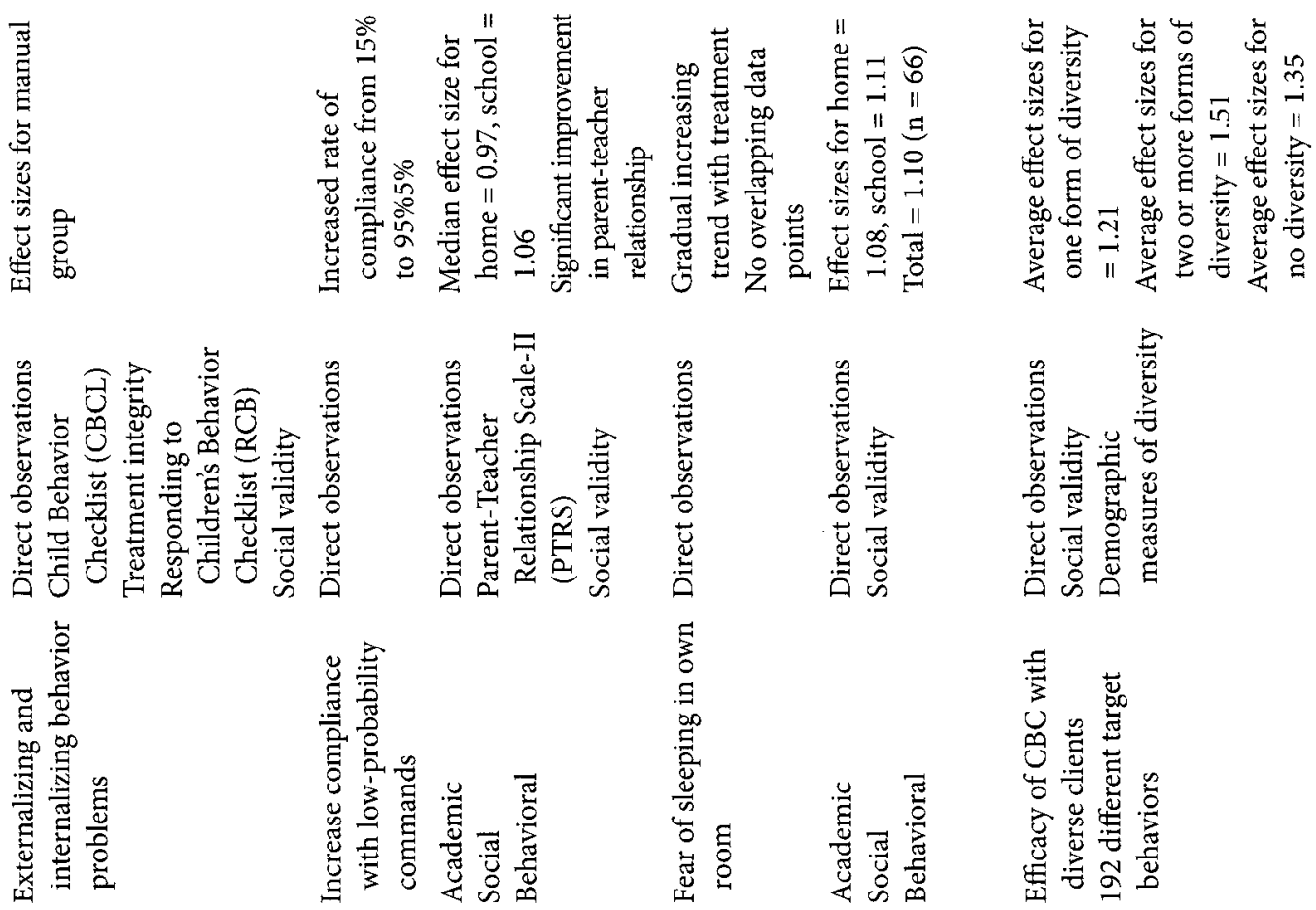

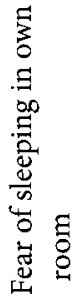

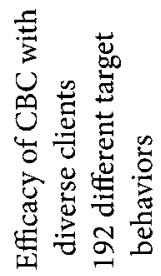

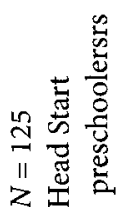

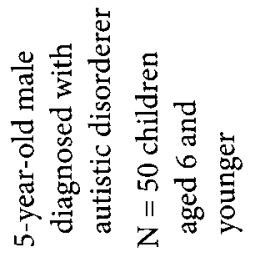

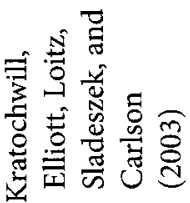

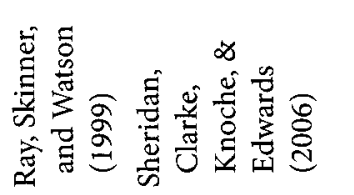

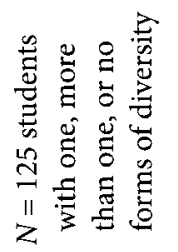

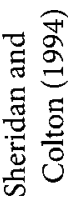

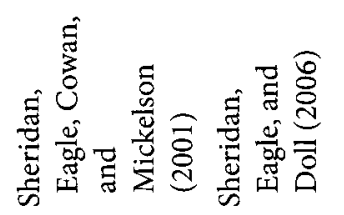




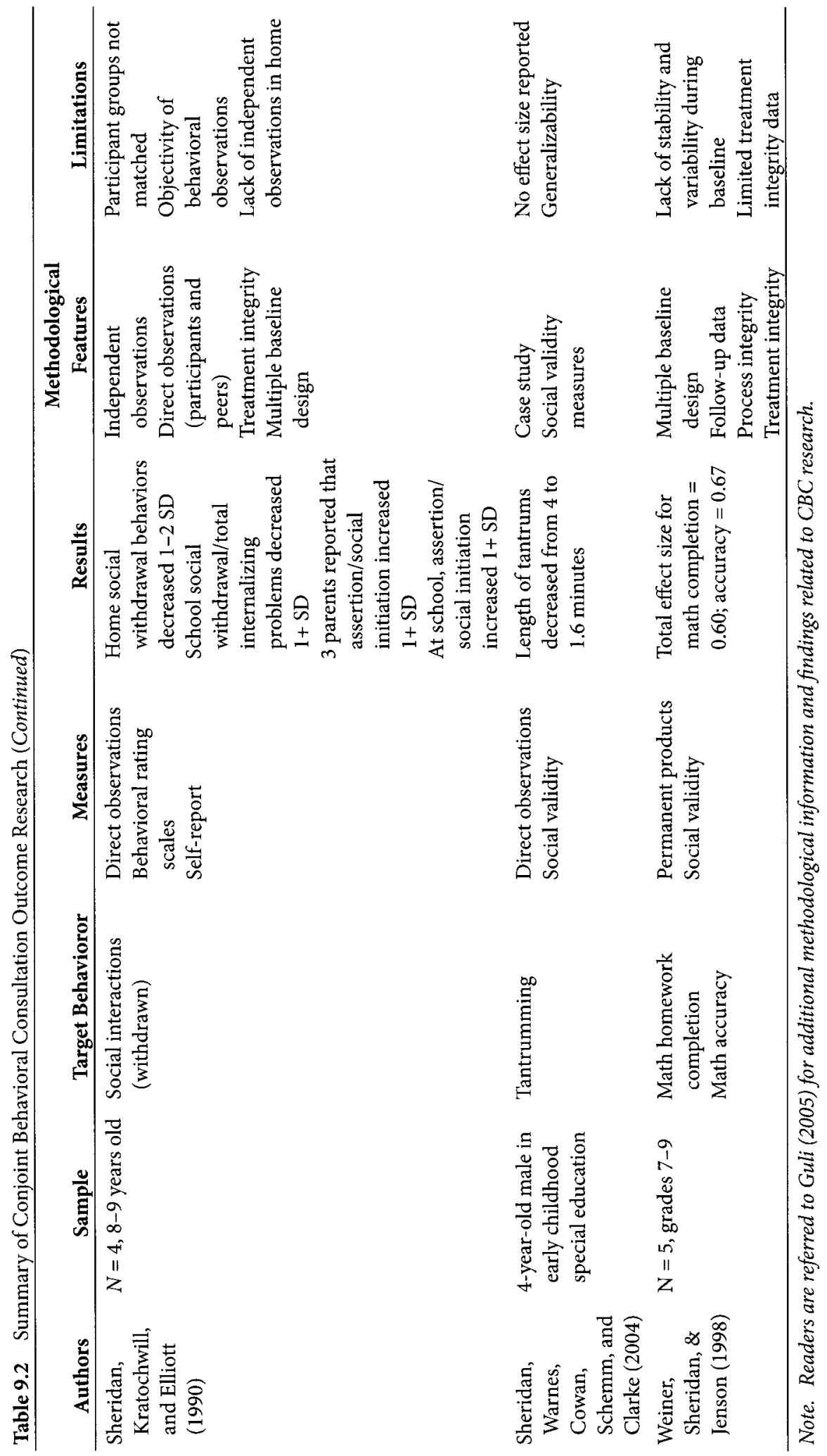


designs. Each of the studies was subjected to comprehensive and rigorous review of methodological strengths and weaknesses. CBC research was included in this review due to its emphasis on consultation as the structure for service delivery.

Within the context of the task force criteria, CBC was found to hold promise as an evidencebased parent consultation model. Specifically, relative to other parent consultation models, CBC provided the strongest evidence for producing significant school-related outcomes. Furthermore, parent consultation studies receiving the highest ratings for key methodological features were those using a model of joint parent-teacher consultation, including CBC. All but one of the highest ratings for both significant outcomes and clinical significance were received by joint models of parent-teacher (i.e., conjoint) consultation.

Sheridan et al. (2001) reported the outcomes of 4 years of federally funded CBC studies. Thirty graduate student consultants provided $\mathrm{CBC}$ services to parents and teachers of 52 students with disabilities (such as behavior disorders, learning disabilities, and attention deficit/hyperactivity disorder [ADHD]) or who were at risk for becoming eligible for special education services. Efficacy of $\mathrm{CBC}$ in terms of ameliorating target concerns was evaluated in each case by computing effect sizes (ESs) across home and school settings. In addition, a prediction model was tested based on client age, case complexity, and symptom severity. Perceptions of effectiveness, process acceptability, and consultee satisfaction with CBC services were also assessed.

Average case outcomes were favorable as determined by effect sizes at home and at school. Specifically, the average effect size for CBC case outcomes was $1.10(S D=1.07)$, with home- and schoolbased effect sizes averaging $1.08(S D=0.82)$ and $1.11(S D=1.24)$, respectively. Confidence intervals computed around effect sizes revealed that the true population average effect size related to CBC could be found within the range of 0.83 and 1.36 , with $95 \%$ confidence.

These researchers were also concerned with identifying variables that may predict CBC outcomes. Multiple linear regression was used to examine the relationships between client age, case complexity (i.e., number of target behaviors), severity of symptoms (i.e., rated by parents and teachers prior to $\mathrm{CBC}$ ), and individual effect sizes. A model fitting client age and symptom severity was found to predict school effect size relatively well $\left(R^{2}=.425\right.$, Adjusted $\left.R^{2}=.343 ; P=.008\right)$. Specifically, the older client (11 years of age and older) with less-severe symptoms would be predicted to experience higher effect sizes with $\mathrm{CBC}$ intervention. On the other hand, the older client with more severe symptoms would be predicted to demonstrate a smaller effect size. Similarly, younger clients (age 5-7 years) with higher severity ratings prior to $\mathrm{CBC}$ services would be predicted to experience higher effect sizes than those experiencing less severity and than older children at all severity levels. Case complexity (i.e., number of target behaviors) was not significant in the models. Likewise, the multiple regression with home effect sizes did not result in any statistically significant model. Thus, client age, symptom severity, and case complexity were not predictive of effects in home settings.

The outcomes of $\mathrm{CBC}$ with a sample of diverse students (experiencing one, more than one, or no forms of diversity) was reported by Sheridan et al. (2006). Behavioral change, goal attainment, acceptability, satisfaction, and perceptions of efficacy of the CBC model were measured with 125 students representing varying levels of diversity and with 192 target behaviors. Of the clients, $44 \%$ were diverse in one or more respect. Collectively, $26 \%$ of the clients experienced one form of diversity; $18 \%$ demonstrated two or more. Approximately $23 \%$ of the sample were identified by their parents as racially diverse (non-White); $19.5 \%$ had only one adult living at home, $15.3 \%$ were living in poverty conditions, $6.9 \%$ had mothers who had not completed high school, and $4.8 \%$ spoke a language other than English in the home.

Findings indicated that $\mathrm{CBC}$-mediated interventions yielded generally high effect sizes regardless of the presence of diversity or the number of diverse characteristics exhibited. Average effect 
sizes were 1.21, 1.51, and 1.35 for students experiencing one, two or more, and no forms of diversity, respectively. Social validity measures (i.e., perceptions of goal attainment, effectiveness, acceptability, and satisfaction) also yielded favorable results. Thus, parents and teachers of students experiencing diversity were positive regarding the $\mathrm{CBC}$ process and outcomes.

\section{Experimental Studies}

In the first empirical study of CBC, Sheridan, Kratochwill, and Elliott (1990) were concerned with increasing the social initiation behaviors of socially withdrawn children. Of particular interest was the demonstration of behavioral generalization to the home setting. Participants in this study were four socially withdrawn children from a rural town in the Midwest ( 3 girls, 1 boy; ages 8-12). There were two treatment conditions in the study (i.e., $\mathrm{CBC}$ and consultation with teachers only). In the $\mathrm{CBC}$ condition, teachers and parents worked together with a school psychologist consultant; in the teacher-only condition, parents were not included in consultation. In both conditions, children were exposed to the same behavioral treatment (i.e., goal setting, self-monitoring, and positive reinforcement). In the CBC condition, these same procedures were implemented across home and school settings.

A multiple-baseline across-participants design was used to evaluate the effectiveness of the separate consultation interventions. When consultation was undertaken with parents and teachers together, initiations increased in both home and school settings. However, when consultation was undertaken with teachers only, children's initiations increased at school only. Treatment gains at school were maintained for all children in both conditions but were most notable for those in the $\mathrm{CBC}$ condition. Although the traditional use of $\mathrm{BC}$ with teachers was found to be effective in increasing the social initiation behaviors of socially withdrawn children at school, both generalization and maintenance of treatment effects appeared to be stronger when conjoint consultation procedures were utilized. Social validity and treatment integrity measures were also included and yielded positive results.

A second outcome study evaluated the effects of $\mathrm{CBC}$ combined with a behavioral training and reinforcement program with three Caucasian boys between the ages of 8 and 9 diagnosed with ADHD and exhibiting performance deficits in their cooperative play behavior (Colton \& Sheridan, 1998). A behavioral social skills treatment package was implemented within the context of CBC to address the children's observed social deficits. The behavioral social skills treatment program consisted of four major components: (a) social skills coaching and role-play, (b) a home-school communication system, (c) self-monitoring of recess behaviors, and (d) positive reinforcement.

Outcome measures in this study included direct observations of positive interaction behaviors and behavioral rating scales. A multiple-baseline across-participants design was used to evaluate the effects of the CBC/social skills treatment program on target children's cooperative play behaviors. All participants increased positive play behaviors with peers during treatment phases. Social comparison data (i.e., involving a comparison with same-gender classmates identified by classroom teachers as having adequate social skills) revealed that all children increased their positive interactions to a level that approached that of normal comparison peers. Parents and teachers reported that the procedures were acceptable (based on responses on the BIRS revised for consultation procedures (Von Brock \& Elliott, 1987), and child responses on the Children's Intervention Rating Profile (CIRP; Witt \& Elliott, 1985) suggested that they found the social skills intervention highly acceptable.

A variation of traditional, individualized CBC was evaluated by Weiner, Sheridan, and Jenson (1998), who implemented consultation services in a group format. Parents and teachers of five junior high school (eighth and ninth grade) students with homework concerns served as participants in this study. Given the age of the sample, students also participated in the CPAI and CPEI 
meetings. A multiple-baseline across-participants design was used to evaluate the effects of $\mathrm{CBC}$ on math homework completion and accuracy. A structured homework intervention program (Olympia, Jenson, \& Hepworth-Neville, 1996) was used to standardize strategies across participants. The primary components of the program were self-recording, home-based structure and supervision, and positive reinforcement.

Moderate effect sizes were yielded for both homework completion (ES $=0.60)$ and accuracy (ES $=0.67$ ). Parents and teachers reported satisfaction with outcomes and beliefs that the consultation goals were mostly or completely met as assessed with the BIRS Effectiveness factor (Von Brock \& Elliott, 1987) and GAS (Kiresuk et al., 1994), respectively. Parents and teachers reported high levels of acceptability on the BIRS Acceptability factor, and consultees were generally satisfied with the consultant as measured by the CEF.

Kratochwill, Elliott, Loitz, Sladeczek, and Carlson (2003) conducted a study of the differential effects of CBC using two methods of consultee intervention support: manual based and video based. Using a pretest-posttest repeated-measures experimental design, the investigators evaluated outcomes of CBC-manual, CBC-video, and control group using multiple measures (Child Behavior Checklist, Achenbach, 1991a; Teacher Rating Form, Achenbach, 1991b; Social Skills Rating Scale, Gresham \& Elliott, 1990). The sample was comprised of 125 Head Start children, parents, and teachers. Target behaviors included aggression, compliance, and "other" behaviors such as participating, staying on task, and joining a group. Parents' and teachers' goal attainment scores characterized students as meeting their overall behavior goals. Specifically, $75 \%$ of parents in the manual group and $95.5 \%$ of parents in the video group reported progress toward goal attainment. For teachers, $60 \%$ in the manual group and $73.1 \%$ in the video group reported similar progress. Reliable change indices (RCI; Gresham \& Noell, 1993) were computed for the standardized measures to determine whether reported changes in behaviors pre- to posttest were significant. Across outcome measures, an average of $46.08 \%$ and $31.37 \%$ of RCIs were deemed statistically significant in the manual and video conditions, respectively. This is in comparison to $25.42 \%$ in the control condition. Contrary to these positive findings, effect sizes were negligible. Parents and teachers reported high rates of treatment acceptability and satisfaction with the manual and videotape treatment programs.

\section{Case Studies}

Some systematic CBC case studies have also been conducted. In a carefully controlled set of case studies, the model was evaluated with academically underachieving children (Galloway \& Sheridan, 1994). Participants were six primary grade students (Grades 1-3) who often failed to complete math assignments on time and with accuracy. They all demonstrated performance rather than skill deficits. In two separate sets of case studies, the investigators evaluated the effectiveness of a standard intervention with and without the inclusion of CBC. Both studies involved the use of a manualized home note system, in which teachers recorded daily performances in math as well as process behaviors intended to help them complete work (e.g., pencil ready and papers out). The home note also included a checklist to help remind parents of what to do at home and served as a measure of treatment integrity.

The investigators used $\mathrm{AB}$ with replication designs to assess outcomes of the home note and $\mathrm{CBC}$ interventions. All three children in the home note-only case studies showed improvements in math completion and accuracy; however, their performance continued to be variable.

As in the home note condition, all children in the home note with $\mathrm{CBC}$ condition demonstrated improvements in math completion and accuracy, but the gains were greater and more stable. Findings in the $\mathrm{CBC}$ case studies also suggested enhanced treatment integrity, maintenance of treat- 
ment gains at follow-up, and consumer acceptability. Furthermore, parents in the CBC condition adhered more faithfully to the treatment regimen than did parents in the home note-only case studies, which may be one reason for the greater treatment effects.

Another case study involved a child displaying irrational fears (Sheridan \& Colton, 1994). In this case, a kindergarten teacher referred a 6-year-old boy with sleep disturbances. Due to unfounded fears, the child slept in his parents' room all night, every night for more than 2 years. The goal for consultation in this case was to get the child to sleep in his own room on a consistent basis.

Treatment involved a fading of environment and positive reinforcement procedure in which positive reinforcers were delivered each time the child slept in a spot that moved successively closer to his own room. An $\mathrm{AB}$ changing criterion design was used, with the criterion adequate performance demonstrated over two occasions at each successive level, moving the boy closer to his own room. Dramatic, immediate improvements were observed in this case. Two weeks of baseline showed 0 occasions of sleeping in his own room and 14 occasions of sleeping on the floor of his parents' room. Six steps were identified during treatment that involved the child moving successively closer to his room. The child demonstrated immediate effects, with perfect performance at each level until he met the goal of sleeping in his bed. Likewise, he demonstrated no regression at a 1-month follow-up.

Ray, Skinner, and Watson (1999) implemented CBC in the case of a 5-year-old boy with autism, who demonstrated problem behaviors including aggression and noncompliance. Compliance behaviors appeared to be related to the person issuing the command, with greater levels of compliance associated with his mother as compared to his teacher. The intervention plan involved the issuance of high-probability command sequences (simple, easy-to-perform tasks) immediately preceding low-probability commands (those typically preceding noncompliance and problem behaviors). As part of consultation, the parent and teacher received instruction on issuing commands, which included sharing information, modeling, and practicing effective commands. Multiple phases of the intervention were instituted to allow for the transfer of stimulus control from the parent to the teacher in the classroom environment. Across eight phases of intervention and a final generalization phase, the child gradually demonstrated high rates of compliance with teacherissued commands. Compliance with teacher commands increased from 15\% during baseline to $95 \%$ and $100 \%$ during the final intervention and generalization phases, respectively.

Gortmaker, Warnes, and Sheridan (2004) reported the outcomes of a case study of a 5-yearold child with selective mutism. $A n A B$ case study with follow-up design was used to evaluate the effects of the CBC-mediated intervention. The interventions used in this case included programming common stimuli and positive reinforcement. Specifically, because school was the only setting in which the child would not speak, talking was established with the teacher in an alternative location outside the classroom. Once the child established speech with the teacher outside the classroom, reinforcers were delivered in the classroom as he gradually spoke in the classroom. On intervention implementation, a gradual positive trend was seen in the child's speaking behaviors. In addition, the child spoke to multiple persons in the school setting (e.g., different teachers and peers) and spoke in front of groups of peers with seeming comfort. Both the child's parent and teacher reported high levels of acceptability for the process on the BIRS Acceptability factor. Satisfaction with the consultant was also high, as determined by responses on the CEF.

In an article describing CBC within a context of "family-centered" services, Sheridan, Warnes, Cowan, Schemm, and Clarke (2004) described a case study of a 4-year-old male attending early childhood special education. The target concern on $\mathrm{CBC}$ referral was tantrumming behavior in the school, home, and public settings, with a specific goal of decreasing the duration of tantrums. The intervention designed to address the concerns of consultees was comprised of antecedent control 
and differential reinforcement. Specifically, the child was provided with choices for activities and was ignored when tantrumming occurred. When he responded appropriately, the child was reinforced through verbal praise and tactile stimulation. Behavioral data indicated that the goal was met quickly on intervention implementation. The child's parent and teacher both reported that their goals were completely met, as indicated via GAS. Both the parent and teacher also reported high levels of acceptability perceptions of effectiveness, as assessed with the BIRS.

Illsley and Sladeczek (2001) reported five case studies of children with significant conduct problems, including aggression, compliance, and socially inappropriate behaviors. In addition, this series of case studies sought to identify changes in parent knowledge and skill related to effective parenting practices. $\mathrm{CBC}$ was effective in producing positive changes in the children's conduct problems at home. All children made significant progress on behaviors targeted for intervention, with decreases in aggressive behavior and increases in compliance and socially appropriate behaviors. As a group, parents tended to demonstrate improvements in their knowledge of child management strategies, increased their use of praise, and were less critical of their children following CBC. However, much variability in parent outcomes was observed.

\section{Review of Conjoint Behavioral Consultation Process Research}

In addition to improving child outcomes related to behavioral, social, or academic targets, another primary objective of $\mathrm{CBC}$ is to engage parents and teachers in collaborative problem solving (see Table 9.1). The manner in which this collaborative relationship is cultivated through the verbal processes of $\mathrm{CBC}$ has become the focus of much-needed investigation. Next, we discuss the research investigating relational communication patterns of the $\mathrm{CBC}$ process. A summary of this research is in Table 9.3 .

\section{Relational Communication Patterns}

Erchul et al. (1999) sought to explain, through an investigation of relational control, the relational communication patterns that occur within CBC. Analyses conducted with the use of relational coding systems emphasize the connectedness of individuals within a conversation, along with the pragmatic (i.e., control-related) aspects of messages. BC research investigating dimensions of relational control (i.e., Erchul, 1987) borrowed the terms domineeringness and dominance from previous relational communication research. In the study, Erchul and his colleagues defined domineeringness as an index of an individual's directiveness or attempt to define or structure relationships throughout consultation. Dominance was considered to be an index of an individual's demonstrated influence or success in defining the relationship.

The purpose of this investigation was to "map" the patterns of relational control that unfold throughout the CBC process by assessing who is speaking to whom and with what degree of relational control. This study was conducted using a relational coding measure known as the family relational communication control coding system (FRCCCS; Heatherington \& Friedlander, 1987). This system allows for the analysis of the unique characteristics of group communication, such as statements made to multiple recipients and interruptions in reciprocity. Four $\mathrm{CBC}$ cases consisting of 12 interviews were audiotaped, transcribed, and coded in terms of domineeringness and dominance using the FRCCCS. Across the 12 interviews, 9,696 individual messages were analyzed.

Comparisons of the present study were made with earlier work conducted by Erchul (1987) investigating relational communication patterns in $\mathrm{BC}$. The analysis revealed that consultants and teachers participating in $\mathrm{CBC}$ displayed similar levels of domineeringness as their $\mathrm{BC}$ counterparts. In addition, $\mathrm{CBC}$ consultants appeared to be far less dominant than $\mathrm{BC}$ consultants, with 


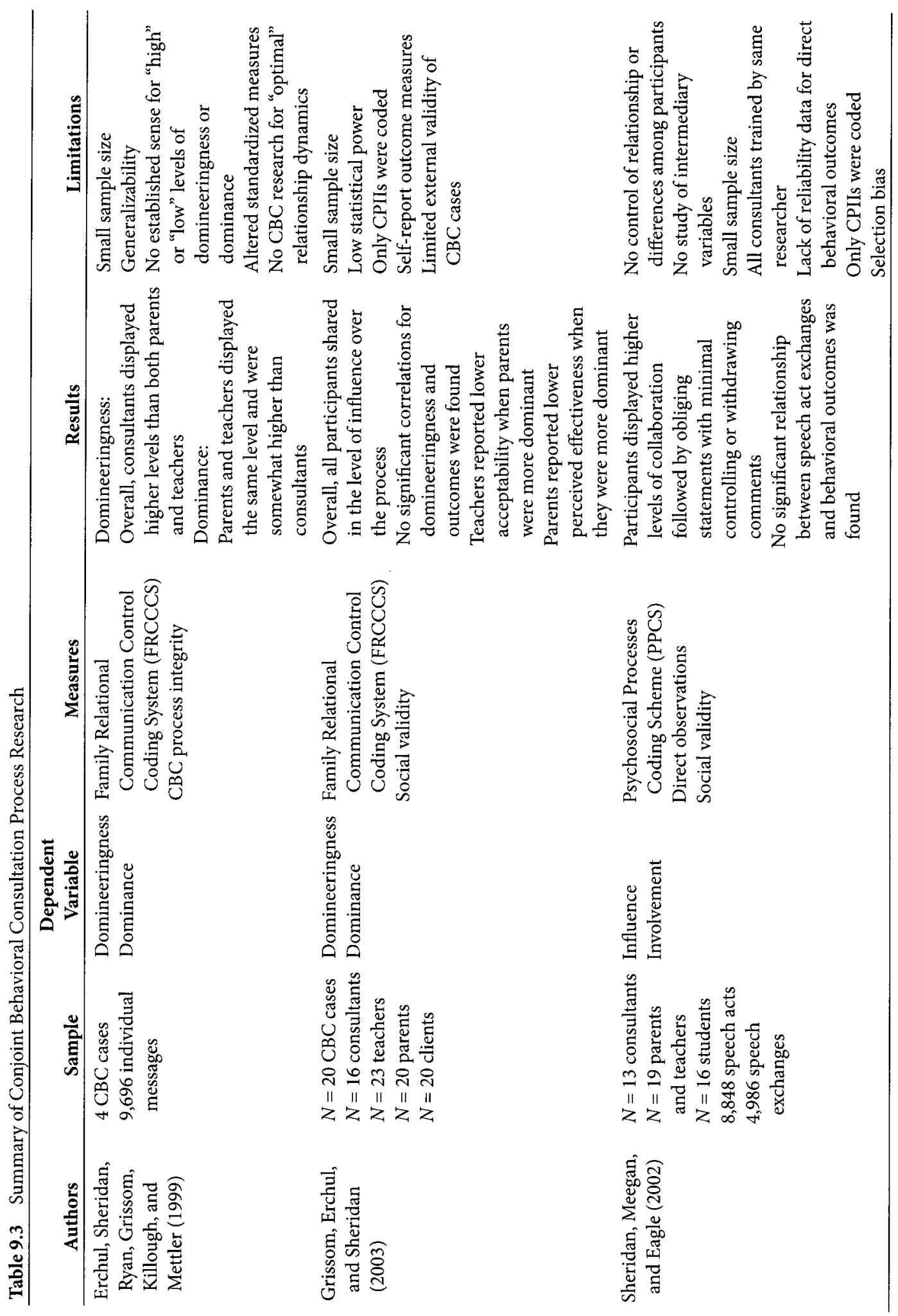


teachers receiving similar scores across groups. Thus, teachers appeared more dominant than the consultants in $\mathrm{CBC}$ but not in $\mathrm{BC}$. These findings suggest that within the $\mathrm{CBC}$ process, no single individual attempts to direct or influence the other members at disproportionate levels; rather, communication patterns tend to be more bidirectional and reciprocal. In terms of relational control theory, such evidence supports the notion that $\mathrm{CBC}$ is a collaborative process involving symmetrical and reciprocal relationships. The authors suggested that it may be the interpersonal dynamics of the $C B C$ triad that lead to a greater degree of shared influence among participants, as opposed to the BC dyad. Thus, $\mathrm{CBC}$ appears to be more of a collaborative service delivery method that facilitates equal relationships, whereas $\mathrm{BC}$ may be more appropriately viewed as involving a complementary relationship.

In a similar study, Grissom, Erchul, and Sheridan (2003) investigated aspects of interpersonal control within the context of $\mathrm{CBC}$ in relation to case outcomes. Measures of dominance and domineeringness were assessed using the FRCCCS and compared against outcome measures of acceptability/effectiveness of $\mathrm{CBC}$, consultant effectiveness, and attainment of consultation goals. CPIIs for $20 \mathrm{CBC}$ cases were used in the coding of the relational control variables (as per Erchul \& Schulte, 1990). It was hypothesized that there would be: (a) significant positive correlations between consultant domineeringness and dominance and parent and teacher outcome ratings; (b) significant negative correlations between teacher domineeringness and dominance and parent and teacher outcome ratings; and (c) significant negative correlations between parent domineeringness and dominance and parent and teacher outcome ratings. Correlation analysis between the relational communication variables of domineeringness and dominance and the three outcome measures failed to produce any significant relationships for the first two hypotheses. Perceptions of outcomes in $\mathrm{CBC}$ were not significantly related to attempts to influence (i.e., domineeringness) and demonstrated influence (i.e., dominance) by consultants and teachers. The relationship between parent domineeringness and outcome measures also was not significant; however, parent dominance was significantly related to two outcome measures. Specifically, as parents influenced the parent-consultant dyadic relationship, the acceptability/effectiveness ratings given by teachers was lower. This finding indicates that the verbal communication between a dyad is related to the perceived outcomes of the third individual. The authors speculated that teachers' lower perceptions of acceptability and effectiveness may be due to unmet expectations for the consultant to be more directive with the process.

In addition, parent dominance within the parent-consultant and parent-teacher dyad was associated with less-favorable parental goal attainment ratings. Thus, as parents demonstrated more influence in the CNII, they reported less-positive behavioral outcomes for their child. Two possible explanations for this finding were proposed. First, parents may view consultation as a means for gaining social support, with problem solving a secondary function of the process. Second, parent dominance within the CNII may interfere with problem identification, which has been identified as an important component of successful consultation (Bergan \& Tombari, 1976). Previous research in BC demonstrated similar results, with teacher attempts of control over the process relating to less-positive outcomes (e.g., Erchul, 1987; Erchul \& Chewning, 1990; Witt, Erchul, McKee, \& Pardue, 1991). Such findings suggest that control within the consulteeto-consultee and consultee-to-consultant relationships may be an important factor influencing perceptions of case outcomes.

Both of the studies described explored relational communication patterns within the verbal exchanges of $\mathrm{CBC}$. In the next section, research evaluating the social context of verbal exchanges within $\mathrm{CBC}$ is reviewed. 


\section{Social Context}

Sheridan, Meegan, and Eagle (2002) examined the nature of the social context in CBC and its relationship to case outcomes (i.e., effect sizes, perceived effectiveness/acceptability of consultation procedures, and satisfaction with the consultant). The Psychosocial Processes Coding Scheme (PPCS; Leaper, 1991) was used to assess two dimensions of communication function within CBC: influence and involvement. Influence referred to the degree to which a speech act (i.e., a phrase or utterance bound by intonation, pauses, or grammar that conveyed a single message) attempts to control the task in consultation or the extent to which a statement directly or indirectly influences the process. Involvement referred to the degree to which a speech act facilitates or hinders the social relationship. Direct and indirect levels of these two dimensions then create four main categories of speech acts: (a) collaborative speech is high in both influence and involvement, (b) controlling speech is high on influence and low on involvement, (c) obliging speech is low on influence and high on involvement, and (d) withdrawing speech is low on both influence and involvement.

Analyses were conducted using 30 -minute segments of 16 CPIIs. This sample yielded 8,848 codable speech acts and 4,986 codable speech act exchanges. Descriptive analysis of the speech acts revealed that individual speech acts among participants were highly collaborative, followed by obliging, with negligible amounts of controlling or withdrawing messages. More specifically, when consultants were not making collaborative statements, they were obliging rather than controlling. Such results indicate that the social context of $\mathrm{CBC}$ is conducive to the development of collaborative partnerships across home and school settings. In addition, effect sizes were found to be meaningful and positive. These findings suggest that not only were positive relationships formed, but also they were effective in addressing concerns on behalf of the child.

Up to this point, a review of outcome and process research has demonstrated that CBC is an effective, collaborative process. The following section reviews social validity findings related to participants' perceptions of the acceptability, goal attainment, and helpfulness of CBC.

\section{Review of Social Validity Research}

Social validity has been identified as an important research topic in consultation (Elliott, Witt, \& Kratochwill, 1991). Kazdin (1977) and Wolfe (1978) described social validity as the social significance of the target behavior chosen for treatment, the social appropriateness or acceptability of the treatment procedures, and the resulting behavior change. Specifically, the aims of social validity research are to determine the degree to which (a) treatment goals are socially significant; (b) treatment procedures are considered socially appropriate; and (c) treatment effects are clinically meaningful.

In the consultation literature, the predominant focus of social validity research is centered on treatment acceptability. Kazdin (1980) defined treatment acceptability as "judgments of lay persons, clients, and others of whether the procedures proposed for treatment are appropriate, fair, and reasonable for the problem or client" (p. 493). GAS (Kiresuk et al., 1994) is another social validity measurement that provides a subjective account of how consultation goals have been achieved. The $\mathrm{CBC}$ literature has also examined social validity through parent and teacher perceptions of helpfulness. Helpfulness is characterized as (a) responsiveness to client needs, (b) promotion of competency acquisition, and (c) promotion of partnership and collaboration among systems (Dunst, Trivette, Davis, \& Cornwell, 1994).

CBC is a consultation model that has been recognized as acceptable (Freer \& Watson, 1999; Sheridan \& Steck, 1995; Sladeczek, Elliott, Kratochwill, Robertson-Mjaanes, \& Stoiber, 2001) and helpful (Sheridan, Erchul, et al., 2004) by parents, teachers, and school psychologists. Traditionally, social validity research has used survey methodology to assess hypothetical acceptability 
rather than actual case-specific acceptability. In the section that follows, research examining the social validity of $\mathrm{CBC}$ in both hypothetical and naturalistic contexts is reviewed. Specifically, CBC acceptability, goal attainment, and helpfulness research are discussed. Studies that have as their main focus the social validity of CBC are reviewed in Table 9.4.

\section{Acceptability Research}

An early study by Sheridan and Steck (1995) surveyed a national sample of school psychologists to examine their perceptions of $\mathrm{CBC}$ as an acceptable model of service delivery. The Consultation Questionnaire was used to assess school psychologists' acceptability of $\mathrm{CBC}$. The questionnaire consisted of three sections: (a) demographic and consultant information (i.e., gender, highest degree earned, age of students served, number of years as a practicing school psychologist, and geographic locale of practice); (b) procedural acceptability of CBC (i.e., 15 items from the Acceptability factor of the BIRS); and (c) situational acceptability (i.e., acceptability of four methods of service delivery across 21 student problem situations). The purpose of their study was to (a) evaluate practicing school psychologists' perceptions of $\mathrm{CBC}$, (b) investigate variables that influence its acceptability, and (c) examine the desirability of $\mathrm{CBC}$ with other behavioral modes of service delivery (i.e., direct intervention, parent-only, and teacher-only consultation).

The results of this study indicate practicing school psychologists find $\mathrm{CBC}$ is an acceptable model of service delivery. Overall, $\mathrm{CBC}$ was rated favorably by respondents, and ratings were positive across different problem types and in comparison to other modes of service delivery. School psychologists rated the mean procedural acceptability of $\mathrm{CBC}$ as 5.24 on a 6-point Likert scale, with 6 reflecting high acceptability. The overall mean logistical barriers score was 4.31 (on a 6-point Likert scale with high scores reflecting a lack of logistical barriers). Although school psychologists rated CBC as an acceptable model, they also indicated that logistical barriers, such as lack of time and administrative/ organization support, impacted the overall acceptability of the model. Age of students served, theoretical orientation, and number of years in practice had little influence on the acceptability ratings.

School psychologists also found $\mathrm{CBC}$ to be more acceptable than other modes of service delivery across all problem types (i.e., academic, behavioral, and social-emotional). Further, CBC was rated similarly by school psychologists across all age groups, with the exception of secondary school psychologists rating $\mathrm{CBC}$ and direct service as equally acceptable. These findings suggest that $\mathrm{CBC}$ is perceived by practicing school psychologists as more generally applicable than other modes of service delivery.

Freer and Watson (1999) examined parent and teacher acceptability of three different approaches to BC: teacher-only consultation, parent-only consultation and CBC. Participants in the study were 111 parents of elementary-aged children and 61 elementary and secondary teachers. Each participant received a packet containing the Problem Questionnaire and the Intervention Rating Profile15 (IRP-15; Witt \& Elliott, 1985). The author-developed Problem Questionnaire consisted of a list of 17 common academic (e.g., reading problems), behavioral (e.g., high distractibility), and socialemotional (e.g., trouble making friends) problems. Respondents were asked to select one consultation approach that was most appropriate for each given problem and rated the overall acceptability of each consultation model using the IRP-15.

The results of this study suggest that both parents and teachers find $\mathrm{CBC}$ to be a very acceptable model of $\mathrm{BC}$. The respondents consistently selected $\mathrm{CBC}$ as the most preferred consultation approach for academic, behavioral, and social-emotional problems. Regarding overall acceptability, both parents and teachers rated $\mathrm{CBC}$ as the most acceptable model of $\mathrm{BC}$ (overall mean $\mathrm{CBC}=$ 78.88 , parent only $=63.31$, teacher only $=60.45$ ). These results replicate the findings from Sheridan 


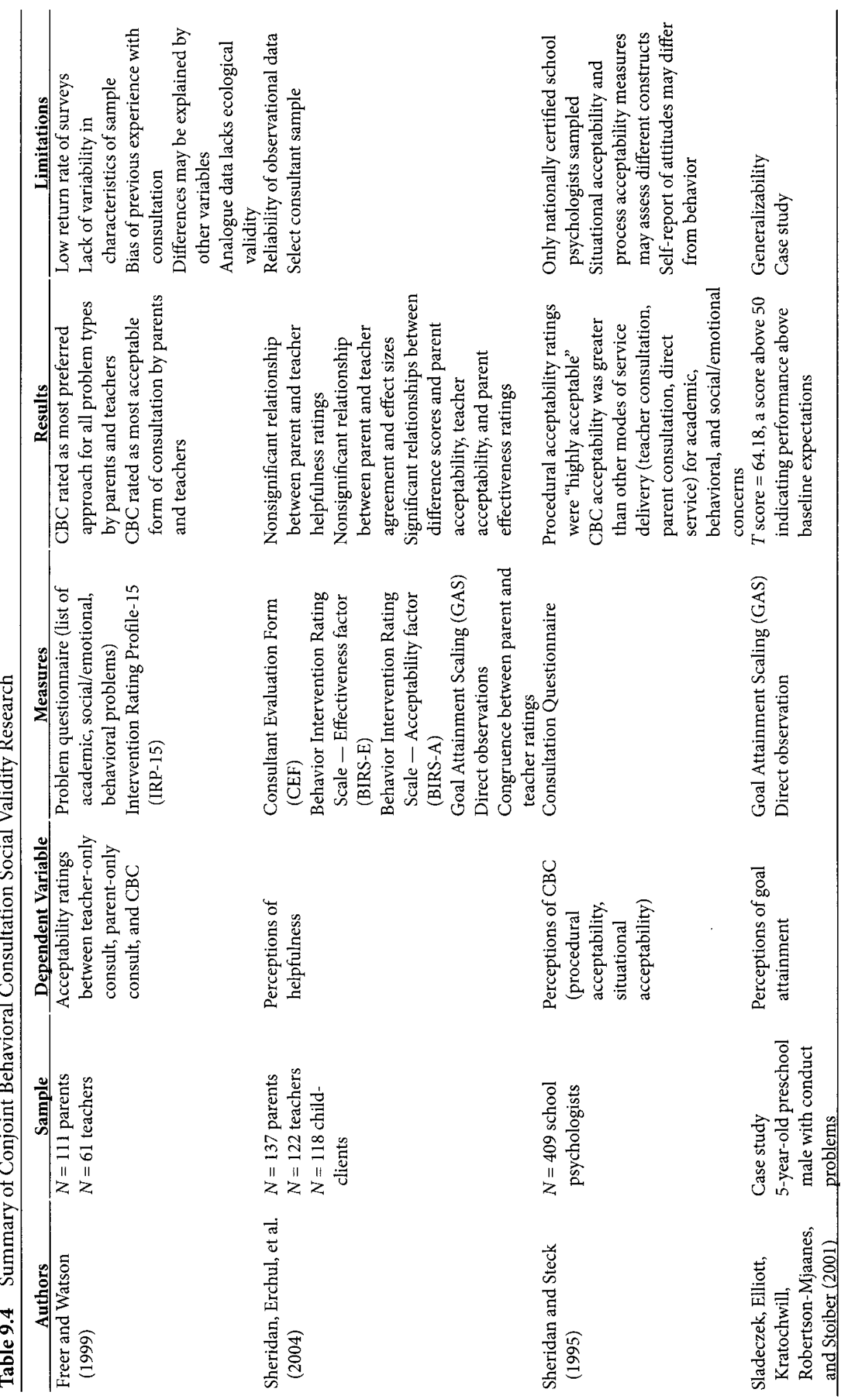


and Steck (1995), who also found that school psychologists reported CBC to be more acceptable than other modes of $\mathrm{BC}$, clearly suggesting that school psychologists, parents, and teachers find $\mathrm{CBC}$ to be an acceptable model of service delivery. However, this research used survey methodology, assessing acceptability of analogue situations rather than actual cases. Thus, the results of these studies are based on hypothetical acceptability not actual experience with the model.

$\mathrm{CBC}$ outcome studies have extended the social validity literature base to include treatment acceptability measurements from field-based casework. A 4-year study examining the effectiveness of $52 \mathrm{CBC}$ cases demonstrated parents and teachers found the CBC process to be acceptable (Sheridan et al., 2001). Specifically, parent and teacher ratings on the Acceptability factor of the Behavior Intervention Rating Scale-Revised (BIRS-R; Elliott \& Van BrockTreuting, 1991) demonstrated that CBC was a highly acceptable process. These results are not unique to this outcome study as multiple $\mathrm{CBC}$ studies have investigated the acceptability of $\mathrm{CBC}$ and have found it to be rated as highly acceptable by parents and teachers alike. Refer to Table 9.2 for a complete list of outcome studies that measured social validity.

\section{Goal Attainment}

Sladeczek and colleagues (2001) investigated participants' perceptions of client goal attainment as a program evaluation procedure within the context of a CBC case study. Specifically, a kindergarten teacher referred a 5-year-old preschool boy, Anthony (fictitious name), for conduct problems. The teacher reported Anthony frequently screamed when angry, and his mother indicated that he was demanding of her attention by clinging to her. The initial goals for consultation were to decrease Anthony's inappropriate behaviors (i.e., decrease screaming behavior at school and decrease clinging behavior at home).

During the CPAI, baseline data were discussed, intervention goals were identified, and intervention strategies were developed. The GAS worksheet was used to identify clear goals for the target behaviors. Baseline data were anchored to the 0 position (i.e., no progress), the best-possible scenario for the target behavior was anchored to the +2 (i.e., goal fully met), and the worst-possible scenario was rated as a -2 (i.e., situation significantly worse). During intervention, the parent, teacher, and consultant met weekly to discuss the degree to which the intervention was effective. The GAS represented an average frequency of the target behavior over a 1-week period and provided the teacher and parent with a common language to communicate the effectiveness of the intervention.

During the last few weeks of the intervention, Anthony's parents and teacher both consistently rated his progress toward the intervention goals at +2 (goal fully met). The GAS scores can also be transformed into a $T$ score, using the computation provided by Cardillo and Smith (1994). At the end of intervention, Anthony had a $T$ score of 64.18 , which indicated positive outcomes for the intervention package implemented within the context of CBC. Despite the positive outcomes of this case study, caution should be executed when generalizing outcomes given the single-participant design. Further, GAS may not be useful for establishing an absolute level of functioning.

Previous outcome studies have also used GAS to assess parent and teacher perceptions of consultation goals. A 4-year investigation by Sheridan et al. (2001) examined the effectiveness of 52 CBC cases. Goal attainment reports indicated that $100 \%$ of parents and $94 \%$ of teachers rated goals as partially or fully met. The following section reviews parent and teacher perceptions of helpfulness during the context of CBC.

\section{Helpfulness Research}

Sheridan, Erchul, et al. (2004) conceptualized CBC as a help-giving model and examined the congruency of parent and teacher perceptions of helpfulness in actual $\mathrm{CBC}$ cases. Although the literature sug- 
gests that congruence among systems increases academic performance (Hansen, 1986; Hill, 2001) and congruence between consultants' and consultees' on their respective roles is associated with positive outcomes of consultation (Erchul, Hughes, Meyers, Hickman, \& Braden, 1992), no research prior to the Sheridan, Erchul, et al. study examined the degree to which congruency of perceptions between parents and teachers has an impact on consultation outcomes. Specifically, Sheridan and colleagues sought to assess (a) the degree to which parents and teachers found the CBC consultant to be helpful and (b) the relationship between parent and teacher agreement and social validity and behavioral outcomes.

Participants included 118 child clients, 137 parents, 122 teachers, and 53 graduate consultants. Measures collected at the time of consultation were used as predictor variables. The Acceptability factor of the BIRS-R was used to assess parent and teacher acceptability of CBC. GAS provided a second assessment of parents' and teachers' perceptions of efficacy through their rating of the degree to which consultation goals were achieved. In addition, the CEF (Erchul, 1987) was used to measure parents' and teachers' perceptions of the consultant's helpfulness. Individual child outcomes were measured via permanent products and direct behavioral observations throughout the implementation of $\mathrm{CBC}$ with effect sizes computed using a no assumptions approach (Busk \& Serlin, 1992).

To assess the congruence between parents' and teachers' perceptions of helpfulness, a Pearson correlation was computed between parents' and teachers' total scores on the CEF. The resulting correlation was nonsignificant. Correlations between parent and teacher agreement scores (i.e., absolute difference score between parent and teacher CEF scores) and effect sizes were also nonsignificant. The results suggest that parents' and teachers' perspectives of the helpfulness of the consultant are not necessarily related to one another. However, negative correlations were found between parent and teacher agreement scores (i.e., CEF difference scores) and social validity outcomes (i.e., teacher acceptability, parent acceptability, and parent effectiveness ratings). These results suggest that as differences between parents and teachers regarding the helpfulness of CBC increased, the acceptability of the model decreased. For parents only, as the differences among parents and teachers increased, the perceptions of the efficacy of $C B C$ decreased.

The acceptability and helpfulness research for the $\mathrm{CBC}$ model is accumulating. Although the research appears to indicate $\mathrm{CBC}$ is an acceptable model of service delivery for parents, teachers, and school psychologists in both hypothetical and naturalistic contexts, more research using a variety of methods is needed. Future research should utilize a combination of methods (e.g., surveys, semistructured interviews, and focus groups) to glean more detailed information on the consultees' perceptions of acceptability.

\section{WHERE WE ARE GOING: EVOLUTION OF CONIOINT BEHAVIORAL CONSULTATION}

Current conceptions of professional practice of family-based service delivery call for a familycentered approach that aims specifically at promoting competence and providing a context for empowerment. Philosophically, calls encouraging the consideration of parents as partners within educational decision making promote services that are responsive to family needs, strengths based rather than focused on deficits, and valid within a family's cultural and ecological contexts. These tenets of family-centered services have influenced the continued conceptualization and evolution of $\mathrm{CBC}$ within an emerging paradigm.

\section{Family-Centered Services}

The significance of the family context on child development has been established (Sheridan, Eagle, \& Dowd, 2005); however, services provided to families to enhance outcomes on behalf of chil- 
dren have not always been delivered through a model that respects existing family strengths, values, and competencies. A family-centered philosophy of practice has been championed by family service providers (Dunst \& Trivette, 1987; McWilliam, Snyder, Harbin, Porter, \& Munn, 2000). The philosophy behind family-centered services emphasizes the importance of promoting positive family functioning by facilitating empowerment on behalf of family members. Such services are characterized by four guiding principles outlined in a model developed by Dunst and Trivette (1987). These principles include (a) intervention efforts must be based on family- (rather than professional-) identified needs; (b) existing strengths and capabilities of the family must be used to enhance developing competencies; (c) personal family social networks must be maximized as a source of support; and (d) helping behaviors must be used to promote new skills and abilities. In addition, family-centered services emphasize the importance of the process by which families work toward goals rather than focus solely on final outcomes.

The guiding principle advanced in this chapter states that partnerships and collaboration between these home and school systems are necessary to promote optimal outcomes for children (Christenson \& Sheridan, 2001; Sheridan et al., 1996). To achieve this goal within a conjoint framework, $\mathrm{CBC}$ research and practice has begun to adopt a philosophy of partnership-centered practices that parallels that of family-centered practices. Within this philosophy, the strengths and capacities of both families and educators are fostered through a positive working relationship that is driven by the jointly identified goals and needs of the child. A strong emphasis is placed on the process by which a partnership between the home and school is developed, which is facilitated through collaboration and communication. In addition, an important role of the consultant is to promote enhanced skills and capacities of families and educators to facilitate empowerment. Importantly, these principles are embodied within and embellish (rather than replace) the structured, evidence-based decision-making context of the $\mathrm{CBC}$ model. The relevance of each partnership-centered principle within the context of $\mathrm{CBC}$ is explored next.

\section{Principles of Partnership-Centered Conjoint Behavioral Consultation}

\section{Partnership-Centered Conjoint Behavioral Consultation Focuses on Jointly Identified Needs and Priorities}

The focus of the $\mathrm{CBC}$ process is determined by the mutually identified priorities and concerns of the educators and caregivers on behalf of the child. It is assumed that these individuals are in the best position to determine the most salient needs of the child within the natural contexts of home and school. By allowing consultees to determine the priorities for consultation with the guidance of a consultant, it is likely that an effective match with the culture and values of homes and schools will be facilitated, and families and educators will be invested in the process (Sheridan, Warnes, Cowan, et al., 2004). The primary objective of the CBC process is then to ensure that these identified needs are met to help the child positively engage in his or her home and school system. To do so, consultants provide opportunities in the initial stages of $\mathrm{CBC}$ for consultees to identify priorities that are most salient to them, rather than focusing on the predetermined targets of the consultant (Sheridan et al., 1996). Consultants also remain flexible in meeting the needs of the parents and teachers by assisting them in developing interventions and data collection measures that fit within the context of the environment (Sheridan et al., 2005). As a result, it is expected that teachers and caregivers are more likely to be invested in the process and willing to carry out intervention plans with integrity. 


\section{Partnership-Centered Conjoint Behavioral Consultation Uses Existing Strengths and Capabilities of Consultees to Promote Developing Competencies in Addressing Concerns}

The principle of using existing consultee strengths and capabilities to promote developing competencies in addressing concerns underscores the belief that all families and educators possess unique strengths and expertise. Specifically, teachers possess knowledge of child development, classroom management, and educational processes, and families have a unique understanding of the individual child and the home environment (Sheridan et al., 2005). The knowledge of the consultees is vital in understanding the distinctive needs of each child and developing culturally sensitive interventions to address concerns. Consultants are called on to assist consultees to identify and mobilize existing strengths and expertise to promote positive functioning on behalf of the child (Sheridan, Warnes, Cowan, et al., 2004). By acknowledging the abilities of the consultees, consultants are in a position to enhance the self-efficacy of parents and teachers to create positive changes in the life of the child (Dunst, Trivette, \& Deal, 1988). It is the task of the consultant to establish an atmosphere that focuses on family and educator strengths and resources rather than deficits. These key components must be systematically acknowledged and utilized as a foundation for intervention planning and implementation.

\section{Partnership-Centered Conjoint Behavioral Consultation Strives to Maximize Social Networks and Resources of Support Across Contexts}

Another aim of the $\mathrm{CBC}$ process is to establish strong linkages across the home and school systems that foster positive support networks long after consultation is terminated (Sheridan, Warnes, Cowan, et al., 2004). Throughout the process, partnerships between home and school are fostered through joint problem solving and responsibility sharing (Sheridan et al., 2005). Both parties are provided equal decision-making opportunities, emphasizing the notion of a true "partnership." Consultants facilitate such a partnership by addressing decision making as a team, ensuring that all parties are allowed power in determining goals and intervention plans. They also attempt to provide a safe atmosphere in which parents and educators feel free to share different perspectives without fear of repercussion while still maintaining positive communication.

\section{Partnership-Centered Conjoint Behavioral Consultation Is Delivered Through Helping Behaviors That Promote New Skills and Abilities for Consultees}

An additional objective of CBC is to provide consultees with the skills and knowledge of how to address identified concerns for their child in the future (Sheridan et al., 1996). Through participation in the process, consultees are provided with the knowledge and practice of using a structured, data-based approach to systematically develop interventions designed to promote positive outcomes. As a result, families and educators are provided with the necessary tools to address future concerns and decrease their dependence on the support of the consultant, thus facilitating empowerment (Sheridan, Warnes, Cowan et al., 2004). Consultants facilitate new skill development by structuring the problem-solving process in such a way that allows consultees to focus their efforts using a systematic approach. Consultees learn to prioritize, define, monitor, and evaluate concerns in the initial stages of the CBC process. Data collected from consultees' observations are discussed with the team and used to guide the process. Consultants refer to this information to help parents and teachers select developmentally appropriate goals and interventions based on meaningful information. In addition, strategies are discussed for how to modify intervention efforts and continue assessment of ongoing treatment goals. Throughout each step 
of the process, consultants provide consultees with rationales for why it is important, thus giving the process away by making it overt.

\section{Partnership-Centered Conjoint Behavioral Consultation Emphasizes the Importance of the Process in Addition to Outcomes}

Although one of the main objectives of $\mathrm{CBC}$ has always been to effect positive change on behalf of the child, the process by which parents and educators reach this aim is important. Active engagement and collaboration among parents and teachers are essential in achieving these goals and are vital to the CBC process (Sheridan et al., 1996). Throughout CBC, consultants provide opportunities for consultees to take active responsibility by sharing information and implementing assessment and intervention strategies. Although the role of the consultant is to facilitate and support the process, consultees bear most of the responsibility for assessment and intervention.

\section{WHAT WE NEED TO KNOW: FUTURE RESEARCH AGENDA}

Despite the increasing empirical support for the efficacy and social validity of $\mathrm{CBC}$, clear and important research challenges remain. In light of increasing demands for accountability and evidence of empirical support for interventions implemented in school and other practice settings, the demand for broad and rigorous research is omnipresent. In addition, new research questions related to both process and outcome are evident as the $\mathrm{CBC}$ model continues to evolve. As in other forms of consultation research, many of the questions at their most basic levels are concerned with interactions between participants and systems, exhibit mediating and moderating variables influencing outcomes, and require both depth and breadth in uncovering and understanding their complexity. In this section, we address new and expanding research questions in need of investigation and methodological requirements necessary to move the field of $C B C$ research forward.

\section{New Research Questions}

As in any growing and evolving field, the proliferation of research in $\mathrm{CBC}$ paradoxically opens the door for even more empirical investigation covering a broad and expansive scope. Several important areas of research exist, some of which are reviewed here. Examples of research agendas presented include the (a) need to understand conditions under which $\mathrm{CBC}$ is effective, including the setting (where), sample characteristics (for whom), and their relationship to outcomes; (b) effects of CBC on consultee variables such as competence, role construction, and self-efficacy; (c) effects of $\mathrm{CBC}$ on relationships at all levels, including those between parents, teachers, and children; (d) long-term maintenance effects of $\mathrm{CBC}$ outcomes, including maintenance of interventions, partnerships, and relationships between participants; and (e) utility of $\mathrm{CBC}$ as a prevention model. New and sophisticated research designs will be required to address several of these agendas, and they are also explored.

\section{Setting Characteristics}

In practice, $\mathrm{CBC}$ has been implemented in multiple settings (e.g., preschool programs, Head Start settings, and elementary schools). To date, little research has systematically investigated the utility of the model in different practice arenas. There is a need to study the effects of CBC across various contexts, each with its unique challenges. Interactions between settings, samples, targets, and other case-related variables will undoubtedly influence outcomes, and these need to be examined 
empirically. Examples of settings where $\mathrm{CBC}$ should be investigated systematically include pediatric medical settings, early intervention settings, and secondary schools.

$\mathrm{CBC}$ has been offered as a means to integrate systems and services for children with medical and educational needs. For example, Power, DuPaul, Shapiro, and Kazak (2003) suggested that CBC "provides a framework for (a) aligning the family, school, and health systems to facilitate the integration of children with health problems into school, and (b) integrating systems of care into the problem solving process" (p. 89). They went on to indicate that the model "may be highly useful in designing strategies to prevent further health risk and promote resilience in the school context" (p. 90). Similarly, Sheridan, Warnes, Ellis, et al. (2004) offered specific procedures for the inclusion of $\mathrm{CBC}$ within the framework of pediatric psychological services, linking family, school, and medical systems in addressing concerns of a child. Although preliminary outcome data are encouraging, much more research is needed to understand the effects of the model within the interdisciplinary medical environment and inherent challenges linking diverse systems of care.

A second setting within which $\mathrm{CBC}$ may be tested empirically is early childhood settings. As identified in the early intervention literature, factors that maximize effectiveness of early intervention efforts include continuity among caregiving systems, involvement of key stakeholders, positive relationships among caregivers, and a family-centered approach (Dunst \& Trivette, 1987; Early, Pianta, Taylor, \& Cox, 2001). Indeed, these characteristics represent some of the main principles of $C B C$, suggesting the potential usefulness of the model within early intervention contexts. Important research questions within this setting include effects of CBC on young children's academic development, self-management, and social skills; the utility of CBC as a means of engaging families as defined in early childhood special education law; the role of $\mathrm{CBC}$ in the development of Individualized Family Service Plans; and the degree to which the structured, collaborative $\mathrm{CBC}$ process can be integrated into home visits and other early childhood service delivery contexts.

The majority of practice and research in $\mathrm{CBC}$ has focused on services within elementary school programs. The effectiveness of the model within other educational settings is virtually unknown. For example, the context and nature of secondary school programs are qualitatively and structurally distinct. School organization, staffing, and size are variables that potentially affect the manner in which CBC services can be delivered and the type of effects that can be expected. Furthermore, the age of students served in secondary settings may influence the manner in which services are delivered. For example, the inclusion of students within the $C B C$ process may be necessary to increase ownership of the process (Schemm, Dowd, \& Sheridan, 2002; Schemm \& Sheridan, 2002). $\mathrm{CBC}$ research within secondary settings is lacking.

\section{Sample Characteristics}

Research aimed at understanding participant characteristics and their relationship to CBC outcomes has yet to be conducted. There is a clear need in consultation research generally (Ingraham, 2000), including CBC research specifically (Sheridan, 2000), to understand empirically the effects of services on diverse samples. Developments in the area of evidence-based interventions (EBIs) have sorely neglected samples of culturally diverse participants (Doyle, 1998; Kratochwill \& Stoiber, 2002). Attention to the effects of consultation and interventions for specific diverse groups of children has been encouraged by leaders in the EBI movement (e.g., American Psychological Association Division 16/Society for the Study of School Psychology Task Force on EBIs), who recommend evaluation of treatments and computation of separate effect sizes for individuals demonstrating cultural diversity (Kratochwill \& Stoiber, 2002). 
Conceptual discussions of CBC's use with culturally diverse clients have begun to appear. Specifically, Sheridan (2000) defined multicultural CBC as "a home-school consultation relationship wherein important individual differences are present among two or more participants (i.e., parent, teacher, student, school psychologist-consultant) with respect to association with distinct cultural group(s) ... includ[ing] sociodemographic (e.g., race, gender, national origin, class, language) as well as less tangible features of individuals (e.g., beliefs, attitudes, values) and schools (e.g., norms, customs)" (p. 345). Features of CBC, such as interactive and collaborative problem solving; distributed decision making; appreciation for cultural values, perspectives, and norms; and relationship building, are consonant with the principles of culturally sensitive services. Relational processes inherent within the CBC model may allow for the recognition and appreciation of individual cultural differences among consultants, consultees, and clients. However, with the exception of a nonexperimental investigation by Sheridan et al. (in press), little research has been conducted that identifies the efficacy of home-school consultation services with a diverse sample.

\section{Effects on Consultees}

One of the stated goals of all forms of $\mathrm{BC}$, including $\mathrm{CBC}$, is enhancing the skills and competencies of consultees. The basis for this goal lies in the assumption that involvement in the CBC process instills new skills in parents and teachers, which can be transferred to their work with other children, in other settings, and exhibiting other behavioral concerns. These goals and assumptions have not been tested heretofore. There is a clear research gap related to what consultees learn as a function of their involvement and how this learning generalizes beyond the immediate CBC case.

Related to the unknown effects on consultee skill development, little is known about the degree to which involvement in active and collaborative home-school decision making affects psychological variables related to teaching and parenting. Hoover-Dempsey and Sandler (1997) offered a model articulating the importance of parents' beliefs about their own role and ability to perform that role as precursors to active and meaningful involvement. Their model also addresses the relationship between teachers' beliefs about working with parents and the importance of parent involvement in learning. Future $\mathrm{CBC}$ research could investigate the degree to which these variables mediate consultee practices and $\mathrm{CBC}$ outcomes. Similarly, an investigation of the degree to which $\mathrm{CBC}$ affects these consultee variables (e.g., alters parent or teacher roles or enhances self-efficacy vis-à-vis crosssystem partnerships and parental engagement in education) is in need of research attention.

\section{Relationship Effects}

A unique goal of $\mathrm{CBC}$ is concerned with enhancing relationships at all levels, including those between parents, teachers, and children. That is, there are clear and unequivocal attempts within $\mathrm{CBC}$ to strengthen relationships and a partnership between parents and teachers in support of children's learning. However, to date researchers have not assessed the degree to which this goal is met in practice. The effects of $\mathrm{CBC}$ as a model that supports family-school partnerships, enhances parent-teacher relationships, and encourages ongoing dialogue and shared decision making among participants is unknown.

Important features implicit in positive family-school relationships include trust and open, bidirectional communication between family members and school personnel (Christenson \& Sheridan, 2001). Some have suggested that the ongoing and frequent contact between consultants, parents, and teachers inherent in CBC practice are potentially useful in building trust and promoting positive communication. These assumptions have not been tested empirically and are in need of research attention. 
A third area of relational research necessary for investigation concerns the effect of CBC on relationships between parents and their children. It is possible that features within $C B C$ may enhance parent-child relationships. For example, the strength-based approach suggested in new conceptualizations of $\mathrm{CBC}$, a focus on solutions rather than problems, active participation in a child's education, and opportunities to support and encourage learning and development may influence parent-child relationships in positive ways. These are important outcomes in need of research attention.

\section{Long-Term Effects of Conjoint Behavioral Consultation Outcomes}

Given the promising immediate effects found in several CBC outcome studies, it is necessary to understand the long-term effects of the model. Whereas some studies have investigated short-term follow-up of CBC (e.g., Galloway \& Sheridan, 1994; Sheridan et al., 1990), no research has extended the investigation of maintenance beyond a few weeks. Research is needed to determine the lasting effects of $\mathrm{CBC}$ interventions and procedures by which to ensure long-term outcomes.

In addition to maintenance of treatment effects on child participants, there is a need to examine the long-term effects of $\mathrm{CBC}$ on parent, teacher, and relational variables. Some of the consultee variables identified in this chapter are worthy of long-term assessment, including the effects on parents' ongoing involvement in their children's educational programs and teachers' continued use of home-school partnership practices.

\section{Conjoint Behavioral Consultation as a Prevention Model}

$\mathrm{CBC}$ outcome research has focused historically on its effects on participants referred for intervention given challenging behaviors or intractable academic concerns. This approach characterizes the $\mathrm{CBC}$ process as one concerned with identified samples in a reactive (i.e., indicated) framework. However, prevention science in contemporary service delivery frameworks supports the benefits of addressing concerns in universal and selective samples as well. That is, emphasis is placed on addressing concerns through large-scale intervention efforts addressing entire groups (as in universal services) or subgroups of children at risk for unhealthy development (selective services; Power, 2003) through early identification and intervention efforts. Research on the role of CBC as an intervention model within preventive service delivery options is clearly warranted.

\section{Design Features in Future Research}

As is evident from the discussion on scope and depth of research needs, the emerging needs and complex issues facing $\mathrm{CBC}$ researchers present significant challenges related to the design and analysis of empirical studies. It is no longer sufficient to ask questions such as, Does CBC work? using traditional univariate or single-participant designs. To further advance the field, researchers must address the daunting issues facing consultation (and CBC) services and attempt to understand a host of methodological issues.

Randomized trials have been regarded as the hallmark of intervention science. Such designs allow researchers to randomly assign participants to experimental and control conditions to test systematically the effects of interventions. Such designs increasingly are becoming the criterion for federally funded research and require serious consideration among consultation researchers. Within such designs, interactions between variables and the identification of specific variables predicting outcomes are possible. Once consultation is demonstrated to be effective under highly controlled experimental procedures, efficacy studies can be conducted to identify factors that are necessary to bring models "to scale." 
The inherent interactions among systems and participants need to be studied to understand the complex dynamics of consultation, including what works, for whom, and under which conditions. In a similar vein, the identification of predictor variables that mediate and moderate outcomes is necessary to discern the relationship between services and outcomes. Longitudinal models that address growth over time, particularly those that attend to the inherent nested nature of research conducted within classrooms and schools, are necessary to move the consultation field forward.

Despite the importance of, and press for, increasingly rigorous methodological designs, it is imperative that important qualitative features of the consultation process and relationships therein are addressed in CBC research. Mixed methods, including rigorous qualitative features of research, are necessary. Such designs will allow more depth in understanding not only what works under which conditions, but also the essential question, Why? Researchers are encouraged to embrace such complex designs with high levels of sophistication based on recommendations in sources such as Creswell (2002) and Nastasi, Moore, and Varjas (2003).

\section{CONCLUSIONS}

$\mathrm{CBC}$ is a structured, indirect model of service delivery by which parents, educators, and consultants work collaboratively to meet a child's developmental and learning needs, address concerns, and achieve positive outcomes by promoting the competencies of all participants (Sheridan \& Kratochwill, 2007). It is operationalized via four stages aimed at (a) identifying and prioritizing a child's target behavior, (b) setting goals and selecting intervention strategies that can be used cooperatively at home and school, (c) implementing a joint plan across home and school settings, and (d) evaluating the plan and monitoring the child's progress toward goals. CBC holds promise as an evidence-based parent consultation model (Guli, 2005). Outcome research has demonstrated CBC to be an effective model for addressing the needs of children who are at risk for academic, behavioral, or social difficulties. Furthermore, research indicates the CBC process establishes a collaborative context for joint problem solving and planning. Research in $\mathrm{CBC}$ has also extended the previous literature on hypothetical acceptability of consultation models to include participant perceptions of acceptability from field-based casework. Parents, teachers, and school psychologists have identified CBC as an acceptable model of service delivery in both hypothetical and naturalistic settings.

Reforms within the education field call for the inclusion of family-centered principles into professional practice to promote competence and empowerment in families. CBC practices parallel and extend those of family-centered services to include a partnership-centered philosophy. Within a partnership-centered framework, the process by which goals are achieved is recognized to be as important as the achievement of positive child outcomes. Active collaboration and communication between the home and school systems are recognized as central to the achievement of positive child and relational outcomes.

This evolution of the $\mathrm{CBC}$ model has established the need for further empirical investigation of both outcomes and processes of CBC. Specifically, future research in this area should be expanded to include (a) conditions under which $\mathrm{CBC}$ is effective, (b) the effects of $\mathrm{CBC}$ on consultee variables, (c) the effects of $\mathrm{CBC}$ on relationships, (d) long-term maintenance effects of outcomes, and (e) the utility of $\mathrm{CBC}$ as a prevention model. To advance the field, researchers should address these complex issues through new and advanced research designs such as randomized trials and mixedmethod approaches.

$\mathrm{CBC}$ research indicates the model is effective, acceptable, and collaborative. By its very design, $\mathrm{CBC}$ is positioned to address the growing demands of schools to be accountable for student outcomes and to form home-school partnerships. There is a clear need to establish and disseminate valid 
training guidelines to encourage school psychology training programs to embrace the CBC model. Clearly, this type of specialized training in consultation and home-school partnerships will prepare future school psychologists to address the increasing needs of children, families, and schools.

\section{ACKNOWLEDGMENTS}

Preparation of this chapter was supported in part by grants funded by the U.S. Department of Education (R305F05284 and H325D030050) and National Institutes of Health (5R01HD046135) awarded to the first author. The ideas and opinions expressed here belong to the authors and do not reflect those of the granting agencies. Appreciation is extended to Elaine Clark, Mary Haskett, Tom Kehle, Tom Kratochwill, Judy Oehler-Stinnett, Dan Olympia, and Ingrid Sladeczek, who provided information on $\mathrm{CBC}$ dissertations completed under their mentorship. Special gratitude is expressed toward all the graduate students, parents, teachers, and children who have participated in $C B C$ research over the decades.

\section{REFERENCES}

Achenbach, T. M. (1991a). Manual for the Child Behavior Checklist/4-18 and 1991 Profile. Burlington: University of Vermont, Department of Psychiatry.

Achenbach, T. M. (1991b). Manual for the Teacher's Report Form and 1991 Profile. Burlington: University of Vermont, Department of Psychiatry.

Bergan, J. R., \& Tombari, M. L. (1976). Consultant skill and efficiency and the implementation and outcomes of consultation. Journal of School Psychology, 14, 3-14.

Brown, M. S. (2004). Effects of early childhood-conjoint behavioral consultation (EC-CBC) on preschool child compliance. Dissertation Abstracts International, $65(08), 2894 \mathrm{~A}$.

Busk, P., \& Serlin, R. (1992). Meta-analysis for single-case research. In T. R. Kratochwill \& J. Levin (Eds.), Single-case research design and analysis (pp. 187-212). Hillsdale, NJ: Erlbaum.

Cagle, M. L. (2003). Conjoint behavioral consultation with parents and teachers of Hispanic children: A study of acceptability, integrity, and effectiveness. Dissertation Abstracts International, 64 (02), 394A.

Cardillo, J. E., \& Smith, A. (1994). Psychometric issues. In T. J. Kiresuk, A. Smith, \& J. E. Cardillo (Eds.), Goal Attainment Scaling: Applications, theory, and measurement (pp. 173-241). Hillsdale, NJ: Erlbaum.

Christenson, S. L. (2004). The family-school partnership: An opportunity to promote the learning competence of all students. School Psychology Review, 33, 83-104.

Christenson, S. L., \& Sheridan, S. M. (2001). Schools and families: Creating essential connections for learning. New York: Guilford Press.

Colton, D. L. (1999). Utilizing behavioral consultation services to support the inclusion of students with learning disabilities in the general education classroom. Dissertation Abstracts International, 59 (11), $4052 \mathrm{~A}$.

Colton, D. L., \& Sheridan, S. M. (1998). Conjoint behavioral consultation and social skills training: Enhancing the play behaviors of boys with attention deficit hyperactivity disorder. Journal of Educational and Psychological Consultation, 9, 3-28.

Creswell, J. W. (2002). Research design: Qualitative, quantitative, and mixed methods approaches (2nd ed.). Thousand Oaks, CA: Sage.

Doyle, A. B. (1998). Are empirically validated treatments valid for culturally diverse populations? In K. S. Dobson and K. D. Craig (Eds.), Empirically supported therapies: Best practice in professional psychology (pp. 93-103). Thousand Oaks, CA: Sage.

Dunst, C. J., \& Trivette, C. M. (1987). Enabling and empowering families: Conceptual and intervention issues. School Psychology Review, 16, 443-456.

Dunst, C. J., Trivette, C. M., Davis, M. \& Cornwell, J. C. (1994). Characteristics of effective help-giving practices. In C. J. Dunst, C. M. Trivette, \& A. G. Deal (Eds.), Supporting and strengthening families. Vol. 1: Methods, strategies and practices (pp. 171-186). Cambridge, MA: Brookline.

Dunst, C. J., Trivette, C. M., \& Deal, A. G. (1988). Enabling and empowering families: Principles and guidelines for practice. Cambridge, MA: Brookline. 
Early, D. M., Pianta, R. C., Taylor, L. C., \& Cox, M. J. (2001). Transition practices: Findings from a national survey of kindergarten teachers. Early Childhood Education Journal, 28, 199-206.

Elliott, S. N., \& Von Brock Treuting, M. B. (1991). The Behavior Intervention Rating Scale: The development and validation of a social validity measure. Journal of School Psychology, 29, 43-52.

Elliott, S. N., Witt, J.C., \& Kratochwill, T. R. (1991). Selecting, implementing, and evaluating classroom interventions. In G. Stoner, M. R. Shinn, \& H. M. Walker (Eds.), Interventions for achievement and behavior problems (pp. 99-135). Silver Spring, MD: National Association of School Psychologists.

Erchul, W. P. (1987). A relational communication analysis of control in school consultation. Professional School Psychology, 2, 113-124.

Erchul, W. P., \& Chewning, T. G. (1990). Behavioral consultation from a request-centered relational communication perspective. School Psychology Quarterly, 5, 1-20.

Erchul, W. P., Hughes, J. N., Meyers, J., Hickman, J. A., \& Braden, J. P. (1992). Dyadic agreement concerning the consultation process and its relationship to outcome. Journal of Education and Psychological Consultation, 3, 119-132.

Erchul, W. P., \& Schulte, A. C. (1990). The coding of consultation verbalizations: How much is enough? School Psychology Quarterly, 5, 256-264.

Erchul, W. P., Sheridan, S. M., Ryan, D. A., Grissom, P. F., Killough, C. E., \& Mettler, D. W. (1999). Patterns of relational communication in conjoint behavioral consultation. School Psychology Quarterly, $14,121-147$.

Finn, C. A. (2003). Remediating behavior problems of young children: The impact of parent treatment acceptability and the efficacy of conjoint behavioral consultation and videotape therapy. Dissertation Abstracts International, 63 (07), 2456A.

Freer, P., \& Watson, T. S. (1999). A comparison of parent and teacher acceptability ratings of behavioral and conjoint behavioral consultation. School Psychology Review, 28, 672-684.

Galloway, J., \& Sheridan, S. M. (1994). Implementing scientific practices through case studies: Examples using home-school interventions and consultation. Journal of School Psychology, 32, 385-413.

Gortmaker, V., Warnes, E. D., \& Sheridan, S. M. (2004). Conjoint behavioral consultation: Involving parents and teachers in the treatment of a child with selective mutism. Proven Practice, 5, 66-72.

Gresham, F. M. (1989). Assessment of treatment integrity in school consultation and prereferral intervention. School Psychology Review, 18, 37-50.

Gresham, F. M., \& Elliott, S. N. (1990). Social Skills Rating System manual. Circle Pines, MN: American Guidance Service.

Gresham, F. M., \& Noell, G. (1993). Documenting the effectiveness of consultation outcomes. In J. E. Zins, T. R. Kratochwill, \& S. N. Elliott (Eds.), Handbook of consultation services for children: Application in educational and clinical settings (pp. 249-273). San Francisco: Jossey-Bass.

Grissom, P. F., Erchul, W. P., \& Sheridan, S. M. (2003). Relationships among relational communication processes and perceptions of outcomes in conjoint behavioral consultation. Journal of Educational and Psychological Consultation, 14, 157-180.

Guli, L. A. (2005). Evidence-based parent consultation with school-related outcomes. School Psychology Quarterly, 20, 455-472.

Hansen, D. A. (1986). Family-school articulations: The effects of interaction rule mismatch. American Educational Research Journal, 23, 643-659.

Haynes, N. M., Comer, J. P., \& Hamilton-Lee, H. M. (1989). School climate enhancement through parental involvement. Journal of School Psychology, 27, 87-90.

Heatherington, L., \& Friedlander, M. L. (1987). Family Relational Communication Control Coding System coding manual. Unpublished manuscript, Williams College, Williamstown, MA.

Hill, N.E. (2001). Parenting and academic socialization as they relate to school readiness: The roles of ethnicity and family income. Journal of Educational Psychology, 93, 686-697.

Hoover-Dempsey, K. V., \& Sandler, H. M. (1997). Why do parents become involved in their children's education? Review of Educational Research, 67, 3-42.

Illsley, S. D. (2003). Remediating conduct problems in children: Examining changes in children and parents following consultation. Dissertation Abstracts International, 64 (4-B), 1904B.

Illsley, S. D., \& Sladeczek, I. E. (2001). Conjoint behavioral consultation: Outcome measures beyond the client level. Journal of Educational and Psychological Consultation, 12, 397-404. 
Ingraham, C. L. (2000). Consultation through a multicultural lens: Multicultural and cross-cultural consultation in schools. School Psychology Review, 29, 320-343.

Kazdin, A. E. (1977). Assessing the clinical or applied significance of behavior change through social validation. Behavior Modification, 1, 427-452.

Kazdin, A. E. (1980). Acceptability of alternative treatments for deviant child behavior. Journal of Applied Behavior Analysis, 13, 259-273.

Kiresuk, T. J., Smith, A., \& Cardillo, J. E. (Eds.). (1994). Goal Attainment Scaling: Applications, theory, and measurement. Hillsdale, NJ: Erlbaum.

Kratochwill, T. R., Elliott, S. N., Loitz, P. A., Sladeczek, I. E., \& Carlson, J. (2003). Conjoint consultation using self-administered manual and videotape parent-teacher training: Effects on children's challenging behaviors. School Psychology Quarterly, 18, 269-302.

Kratochwill, T. R., \& Sheridan, S. M. (1990). Advances in behavioral assessment. In T. B. Gutkin \& C. R. Reynolds (Eds.), Handbook of school psychology (2nd ed., pp. 328-364). New York: Wiley.

Kratochwill, T. R., \& Stoiber, K. C. (2002). Evidence-based interventions in school psychology: Conceptual foundations of the Procedural and Coding Manual of Division 16 and the Society for the Study of School Psychology Task Force. School Psychology Quarterly, 17, 341-389.

Lasecki, K. L. (2001). Normalizing blood glucose levels in children with Type I diabetes: Mystery motivators used within the context of behavioral consultation models. Dissertation Abstracts International, 61 (10), $5231 \mathrm{~B}$.

Leaper, C. (1991). Influence and involvement in children's discourse: Age, gender, and partner effects. Child Development, 62, 797-811.

Lepage, K. M. (1999). Conjoint behavioral consultation: An evaluation of competency-based training through consultant outcomes, consumer satisfaction, and treatment effects. Dissertation Abstracts International, 59 (7), 2363A.

Masten, A. S., \& Coatsworth, J. D. (1998). The development of competence in favorable and unfavorable environments: Lessons from research on successful children. American Psychologist, 53, 205-220.

McWilliam, R. A., Snyder, P., Harbin, G. L., Porter, P., \& Munn, D. (2000). Professionals' and families' perceptions of family-centered practices in infant-toddler services [Special issue: Families and Exceptionality]. Early Education and Development, 11, 519-538.

Morganstein, T. (2003). Peer relations and self-perceptions of boys with behavioral problems. Dissertation Abstracts International, 63 (7), 2458A.

Moscovitz, K. (2004). The effects of group communication processes on treatment outcomes in school-based problem solving teams. Dissertation Abstracts International, 65 (01), 69A.

Mulgia, E. N. (2001). Conjoint consultation versus the directive approach on language arts homework completion and accuracy in elementary school children. Dissertation Abstracts International, 62 (01), 532B.

Myers, L. W. (1997). Conjoint behavioral consultation as an intervention for young children with disruptive behaviors. Dissertation Abstracts International, 57 (12), 7714B.

Nastasi, B. K., Moore, R. B., \& Varjas, K. M. (2003). School-based mental health services: Creating comprehensive and culturally specific programs. Washington, DC: American Psychological Association.

No Child Left Behind Act of 2001, Pub. L. No. 107-110, 115 Stat. 1425 (2002).

Noell, G. H., Witt, J. C., Slider, N. J., Connell, J. E., Gatti, S. L., Williams, K. L., et al. (2005). Treatment implementation following behavioral consultation in schools: A comparison of three follow-up strategies. School Psychology Review, 34, 87-103.

Olympia, D., Jenson, W. R., \& Hepworth-Neville, M. (1996). Sanity savers for parents: Tips for tackling homework. Longmont, CO: Sopris West.

Power, T. J. (2003). Promoting children's mental health: Reform through interdisciplinary and community partnerships. School Psychology Review, 32, 3-16.

Power, T., DuPaul, G. J., Shapiro, E. S., \& Kazak, A. E. (2003). Promoting children's health: Integrating school, family, and community. New York: Guilford.

Ray, K. P., Skinner, C. H., \& Watson, T. S. (1999). Transferring stimulus control via momentum to increase compliance in a student with autism: A demonstration of collaborative consultation. School Psychology Review, 28, 622-628.

Schemm, A. V., Dowd, S. E., \& Sheridan, S. M. (2002, March). Student inclusion in dropout prevention: Utilizing conjoint behavioral consultation: A case study. Paper presented at the annual convention of the National Association of School Psychologists, Chicago. 
Schemm, A. V., \& Sheridan, S. M. (2002, August). Conjoint behavioral consultation: Providing tools for dropout prevention. Paper presented at the annual convention of the American Psychological Association, Chicago.

Schnoes, C. J. A. (2003). Conjoint behavioral consultation, ADHD, and homework: A combined intervention package for middle school youth with $A D H D$. University Microfilms International.

Scope, C. R. (2003). The efficacy of conjoint behavioral consultation to reduce the off-task behavior of elementary school children diagnosed with Attention Deficit Hyperactivity Disorder. Dissertation Abstracts International, 64 (6), 1975A.

Sheridan, S. M. (2000). Considerations of multiculturalism and diversity in behavioral consultation with parents and teachers. School Psychology Review, 29, 344-353.

Sheridan, S. M., Clarke, B. L., Knoche, L. L., \& Edwards, C. P. (2006). The effects of conjoint behavioral consultation in early childhood settings. Early Education and Development, 17, 593-617.

Sheridan, S. M., \& Colton, D. L. (1994). Conjoint behavioral consultation: A review and case study. Journal of Educational and Psychological Consultation, 5, 211-228.

Sheridan, S. M., Eagle, J. W., Cowan, R. J., \& Mickelson, W. (2001). The effects of conjoint behavioral consultation: Results of a 4-year investigation. Journal of School Psychology, 39, 361-385.

Sheridan, S. M., Eagle, J. W., \& Doll, B. (2006). An examination of the efficacy of conjoint behavioral consultation with diverse clients. School Psychology Quarterly, 21, 396-417.

Sheridan, S. M., Eagle, J. W., \& Dowd, S. E. (2005). Families as contexts for children's adaptation. In S. Goldstein \& R. Brooks (Eds.), Handbook of resiliency in children (pp. 165-179). New York: Kluwer Academic/ Plenum Press.

Sheridan, S. M., Erchul, W. P., Brown, M. S., Dowd, S. E., Warnes, E. D., Marti, D. C., et al. (2004). Perceptions of helpfulness in conjoint behavioral consultation: Congruity and agreement between teachers and parents. School Psychology Quarterly, 19, 121-140.

Sheridan, S. M., \& Kratochwill, T. R. (1992). Behavioral parent-teacher consultation: Conceptual and research considerations. Journal of School Psychology, 30, 117-139.

Sheridan, S. M., \& Kratochwill, T. R. (2007). Conjoint behavioral consultation: Promoting family-school connections and interventions. New York: Springer.

Sheridan, S. M., Kratochwill, T. R., \& Bergan, J. R. (1996). Conjoint behavioral consultation: A procedural manual. New York: Plenum.

Sheridan, S. M., Kratochwill, T. R., \& Elliott, S. N. (1990). Behavioral consultation with parents and teachers: Delivering treatment for socially withdrawn children at home and school. School Psychology Review, $19,33-52$.

Sheridan, S. M., Meegan, S. P., \& Eagle, J. W. (2002). Assessing the social context in initial conjoint behavioral consultation interviews: An exploratory analysis investigating processes and outcomes. School Psychology Quarterly, 17, 299-324.

Sheridan, S. M., \& Steck, M. C. (1995). Acceptability of conjoint behavioral consultation: A national survey of school psychologists. School Psychology Review, 24, 633-647.

Sheridan, S. M., Warnes, E. D., Cowan, R. J., Schemm, A. V., \& Clarke, B. L. (2004). Family-centered positive psychology: Focusing on strengths to build student success. Psychology in the Schools, 41, 7-17.

Sheridan, S. M., Warnes, E. D., Ellis, C., Schnoes, C., Burt, J., \& Clarke, B. (2004, July). Efficacy of conjoint behavioral consultation in developmental-behavioral pediatric services. Paper presented the annual conference of the American Psychological Association, Honolulu.

Sladeczek, I. E., Elliott, S. N., Kratochwill, T. R., Robertson-Mjaanes, S., \& Stoiber, K. C. (2001). Application of Goal Attainment Scaling to a conjoint behavioral consultation case. Journal of Educational and Psychological Consultation, 12, 45-59.

Stephan, W. C. (1999). Conjoint behavioral consultation: Delivering treatment for children in the special education program of an elementary school. Dissertation Abstracts International, 60 (3), 1292B.

Von Brock, M. B., \& Elliott, S. N. (1987). Influence of treatment effectiveness information on the acceptability of classroom interventions. Journal of School Psychology, 25, 131-144.

Weiner, R. K., Sheridan, S. M., \& Jenson, W. R. (1998). The effects of conjoint behavioral consultation and a structured homework program on math completion and accuracy in junior high students. School Psychology Quarterly, 13, 281-309.

Witt, J. C., \& Elliott, S. N. (1985). Acceptability of classroom management strategies. In T. R. Kratochwill (Ed.), Advances in school psychology (Vol. 4, pp. 251-288). Hillsdale, NJ: Erlbaum. 
Witt, J. C., Erchul, W. P., McKee, W. T., \& Pardue, M. M. (1991). Conversational control in school-based consultation: The relationship between consultant and consultee topic determination and consultation outcome. Journal of Educational and Psychological Consultation, 2, 101-117.

Wolfe, M. M. (1978). Social validity: The case for subjective measurement or how applied behavior analysis is finding its heart. Journal of Applied Behavior Analysis, 11, 203-314.

Ysseldyke, J., Dawson, P., Lehr, C., Reschly, D., Reynolds, M., \& Telzrow, C. (1997). School psychology: A blueprint for training and practice II. Bethesda, MD: National Association of School Psychologists. 